\title{
An Experiment on First-Price Common-value Auctions with Asymmetric Information Structures: The Blessed Winner ${ }^{1}$
}

\author{
Brit Grosskopf \\ Department of Economics \\ University of Exeter \\ b.grosskopf@exeter.ac.uk
}

\author{
Lucas Rentschler \\ Department of Economics and Finance \\ Utah State University \\ lucas.rentschler@usu.edu
}

\author{
Rajiv Sarin \\ Department of Economics \\ University of Exeter \\ r.sarin@exeter.ac.uk
}

January 11, 2018

\footnotetext{
${ }^{1}$ We thank audiences at the ESA meetings, audiences at the Department of Economics at Texas A\&M University, John Kagel and John Morgan for helpful comments and suggestions. We also thank the associate editor and three referees. Financial support from the Department of Economics at Texas A\&M University and the BID cluster at the University of Exeter is gratefully acknowledged.
} 


\begin{abstract}
In common-value auctions bidders have access to public information, and may also hold private information prior to choosing their bids. The literature has predominately focused on the case in which bidders are ex-ante symmetric and privately informed, and finds that aggressive bidding such that payoffs are negative is common (the winner's curse). In practice, bidders often only have access to public information, and use this information to form (possibly differing) beliefs. In addition, a bidder who is not privately informed may face bidders who are. We examine bidding behavior of both informed and uninformed bidders, and vary the information structure they face. We find that uninformed bidders underbid dramatically and persistently, while informed bidders tend to overbid in the two-bidder case. Our results highlight the importance of correctly modeling the information available to bidders.
\end{abstract}

JEL Classifications: D44; D82; D72.

Keywords: auctions, asymmetric information structures, underbidding, public information. 


\section{Introduction}

An important and well studied class of auctions are those for leases of oil and gas tracts, studied by Hendricks and Porter and co-authors (1987, 1988 and others). ${ }^{1}$ Such auctions are typically referred to as common-value. They share the characteristic that all bidders have access to public information regarding the value of the lease. Bidders may also hold private information about this value prior to choosing their bids. Auctioned offshore tracts typically fall into two categories. In the first, referred to as drainage tracts, some or all of the bidders have access to private information regarding the value prior to bidding. Auctions of drainage tracts include situations in which all bidders have private information, and also cases in which some bidders have private information, while others only have public information. ${ }^{2}$ In the second category, referred to as wildcat tracts, no bidder has access to private information prior to bidding.

The literature on auctions has been largely concerned the case in which all bidders have access to private signals, which might differ in their level of informativeness. We are not aware of any experimental study of first-price auctions which has investigated bidding behavior when some or all of the bidders only have access to publicly available information as is typically the case in wildcat auctions. ${ }^{3}$ Interestingly, wildcat auctions make up the overwhelming majority (83\%) of auctions in the dataset studied by Hendricks, Porter and co-authors. This paper provides a first experimental investigation of these cases while contrasting it with the better studied case in which all bidders observe private signals. As such, we investigate the central information settings faced by bidders in the Hendricks-Porter et al. studies.

Interestingly, the data used by Hendricks, Porter and co-authors shows that the number of bidders in both wildcat and drainage auctions was relatively small, with the overwhelming majority of auctions attracting less than seven bidders. ${ }^{4}$ In fact, auctions with only two bidders account for $24 \%$ of drainage auctions and $18 \%$ of wildcat auctions. If we take out auctions that only attracted one bidder, two bidder auctions make up $41 \%$ of drainage auctions and $29 \%$ of wildcat auctions. ${ }^{5}$ This is particularly interesting as experimental studies of first-price, sealed-bid common-value auctions usually are conducted with four or

\footnotetext{
${ }^{1}$ Some of these papers include Hendricks et al. (1987); Hendricks and Porter (1988); Hendricks et al. $(1989,1993,2003)$.

${ }^{2}$ It has been observed that when there was more than one bidder who held private information, bidders who only had public information tended to drop out of the auction.

${ }^{3}$ While the auctions in Bazerman and Samuelson (1983) did not provide private information to subjects, each subject reported their estimate of the value, and this was taken as an informative signal in the analysis

${ }^{4}$ http://capcp.psu.edu/data-and-software/outer-continental-shelf-ocs-auction-data

${ }^{5}$ While auctions with only two bidders are remarkably common, it is possible that this comes about
} 
more bidders. In order to fill the void, we design an auction experiment with two bidders in three different information structures. The value of the good is common, but uncertain. We vary the number of bidders who have private information at the time they choose their bids. Either both bidders observe signals, as is commonly studied in the literature, or only one bidder receives such private information, while the other only has access to the common knowledge distribution from which the value of the good is drawn. Lastly, we study auctions where both bidders only have access to public information.

In line with other experimental studies, we find that agents with private information tend to overbid, and are susceptible to the winner's curse. Our main finding is that agents who only observe public information systematically underbid, and this behavior persists over time. When no agent has private information the magnitude of this underbidding is overwhelming and this behavior involves not best responding by all players. The underbidding of uninformed agents occurs both when the other bidder is privately informed and when she is not. When all bidders have only public information, this underbidding results in the players getting large profits. Hence, in contrast to previous experimental studies which involved all agents obtaining private information and overbidding, we find that when no agent has private information the winner of the auction may be thought of as "blessed."

The primary contribution of this paper is to uncover the behavior of agents who have only public information about their environment. We argue that the underbidding of such agents cannot be explained by risk and loss aversion, collusion or cursed bidders. While a model of level- $k$ reasoning is qualitatively in line with our results, our estimates suggest that bidders must hold implausible beliefs for this explanation to hold.

We check for the robustness of our observations by increasing the number of bidders from two to four and to six in auctions where no bidders hold private information. We find that, on average, underbidding persists, although the level of underbidding decreases in the number of bidders. When there are two or four bidders, bidders earn a positive payoff. When there are six bidders, the winning bid is aggressive enough that payoffs are negative, on average.

The remainder of the paper is structured as follows. Section 2 introduces the theoretical predictions. Section 3 presents our experimental design, followed by Section 4 which describes our results. Section 6 assesses the ability of alternative bidding models to explain our data.

through endogenous entry. As a result, some bidders may decide on their bids before they know the exact number of bidders. These issues have previously been studied in the experimental literature. For example, Cox et al. (2001) study entry in common-value auctions in environments where the number of bidders is revealed before bids are placed. De Silva et al. (2009) study entry in both common and private value auctions where bidders are not informed of the number of entrants before placing bids. 
Section 5 reports the results of additional experimental sessions which study auctions with two, four and six bidders, where there is only public information available to the bidders. Section 7 contains a concluding discussion.

\section{Theory}

We study the simplest framework which has not been previously studied and which is capable of yielding robust insights. In particular, we examine first-price, sealed-bid auctions with two bidders. The prize has a common but uncertain value $x$, where $x$ denotes the realization of a random variable $X$ with uniform density on $[25,225]$. The distribution from which the prize is drawn is assumed to be common knowledge.

Prior to bidding, each bidder may (or may not) obtain a private signal regarding the value of $x$. If a bidder observes a signal we say she is informed; if she does not we say she is uninformed. We are interested in all the possible information structures that can arise in such a game. In particular, we study auctions with an asymmetric information structure (ASYM), in which only one bidder is informed, auctions where all information is symmetric and public (SPUB), in which neither bidder is informed, and auctions where bidders are ex-ante symmetric but there is private information (SPRIV), in which both bidders are informed.

We denote a signal observed by bidder $i$ as $z_{i}$, which is a realization of the random variable $Z_{i}$. Each signal is an independent draw from a uniform distribution on $[x-8, x+8] .{ }^{6}$ The ex-ante distribution of the signals, and which bidders will observe a signal, is common knowledge.

In addition to whether or not the bidders play the (risk-neutral) Nash equilibrium, we are interested in whether their bids exceed the break-even bidding threshold. We define this threshold to be the bid above which a bidder is expected to earn a negative payoff conditional on winning the auction and assuming the other bidder employs their equilibrium bidding strategy. ${ }^{7}$ In SPRIV auctions such bidding behavior is referred to as the winner's curse, and

\footnotetext{
${ }^{6}$ We use this distribution of values and signals for comparability with the existing literature.

${ }^{7}$ This is a conservative definition of the break-even bidding threshold. In particular, depending on the relevant information structure, it need not be necessary to assume that the opposing bidder bids according to equilibrium. For example, when the opposing bidder is not informed, the expected payoff of a bidder conditional on winning the auction does not depend on the strategy of the other bidder. As such, the break-even threshold could equivalently be defined as simply the expected payoff conditional on winning the auction. When the opposing bidder is informed, the strategy of the other bidder is relevant to the expected payoff conditional on winning. In SPRIV auctions, the break-even bidding threshold is typically defined
} 
its prevalence is the subject of a large literature. ${ }^{8}$

We also examine the information rent earned by informed bidders, which we define as the difference between a bidder's expected payoff when she is informed and when she is not, all else constant. As will be discussed in more detail below, the equilibrium expected payoff of a bidder who does not observe a signal is always zero. Thus, the information rent of an informed bidder is simply her equilibrium expected payoff.

\subsection{Asymmetric information structure (ASYM)}

Consider the case in which only one bidder is informed. We denote her signal as $z_{I}$ (a realization of $Z_{I}$ with distribution $F_{Z_{I}}$ ). Engelbrecht-Wiggans et al. (1983) provide the unique risk-neutral Nash equilibrium of this game. ${ }^{9}$ The risk-neutral Nash equilibrium bid function of the informed bidder is given by

$$
\beta\left(z_{I}\right)= \begin{cases}\frac{z_{I}}{3}+\frac{58}{3} & \text { if } z_{I} \in[17,33) \\ \frac{z_{I}}{2}+\frac{75}{6}+m\left(z_{I}\right) & \text { if } z_{I} \in[33,217) \\ \frac{z_{I}}{3}+\frac{442}{3}+n\left(z_{I}\right) & \text { if } z_{I} \in[217,233]\end{cases}
$$

where $m\left(z_{I}\right)=\frac{32}{3\left(z_{I}-25\right)}$ is the nonlinear portion of the equilibrium bid function when $z_{I} \in[33,217)$ and $n\left(z_{I}\right)=\frac{1}{3}\left(\frac{15200}{z_{I}-313}-\frac{8800}{z_{I}-153}\right)$ is the nonlinear portion of the equilibrium bid function when $z_{I} \in[217,233]$.

In equilibrium, the uninformed bidder employs a mixed strategy such that her distribution of bids is identical to the ex-ante bid distribution of the informed bidder. ${ }^{10}$ We denote the

under the assumption that the bidder with the highest signal will always win, which may involve bidders employing non-equilibrium strategies (see e.g., Casari et al. (2007)). For uninformed ASYM bidders, even if the informed bidder employs a monotonic equilibrium bidding strategy the expected value of the good to a winning uninformed bidder depends on the strategy of the informed bidder. Thus, we define the threshold assuming equilibrium bidding on the part of the opposing bidder, and apply this definition for all types of bidders for consistency.

${ }^{8}$ See e.g., Kagel and Levin (2002), Casari et al. (2007), Kagel and Richard (2001) and Kagel and Levin (1999).

${ }^{9}$ The derivations of the equilibrium bidding strategy, expected payoffs and expected revenue are found in Appendix A.

${ }^{10}$ While the informed bidder's equilibrium ex-ante bid distribution is the same as that of the uninformed bidder, it is not generally the case that the uninformed bidder's best response is to choose a bid distribution which is identical to that of the informed bidder, or vice versa. 
distribution function of this mixed strategy as $Q$, with support on [25, 125], given by

$$
\begin{aligned}
Q(b)= & \operatorname{Prob}\left[\beta\left(Z_{I}\right) \leq b\right] \\
& =F_{Z_{I}}\left(\beta^{-1}(b)\right) .
\end{aligned}
$$

Since, in equilibrium, the uninformed bidder employs a mixed strategy, it must be the case that the expected payoff of any bid in the support of this strategy yields the same expected payoff. Engelbrecht-Wiggans et al. (1983) demonstrate that the uninformed bidder wins only when the informed bidder's signal indicates that $x$ is low, such that the expected payoff of the uninformed bidder is zero conditional on winning the auction. This implies that the ex-ante expected payoff of the uninformed bidder is also zero.

Interestingly, these equilibrium predictions are largely unchanged when the number of uninformed bidders increases. ${ }^{11}$ Engelbrecht-Wiggans et al. (1983) show that the unique class of equilibria in such a game involves the informed bidder bidding according to $\beta\left(z_{I}\right)$, and the uninformed bidders choosing bids on the support $[25,125]$ such that the bid distribution of the maximum uninformed bid is equal to that of $Q(b)$. Both the predicted revenue and the equilibrium payoffs of informed and uninformed bidders is not affected by the number of uninformed bidders. Determining whether or not the behavior of the informed bidder in the lab is invariant to the number of uninformed bidders would be, in our view, an interesting avenue for future research.

The ex-ante expected payoff of the informed bidder, which is also her information rent, is 33.23. ${ }^{12}$ Since the expected revenue of an ASYM auction is the expected value of the prize, less the ex-ante expected payoffs of both bidders, this implies that expected revenue is $125-33.23-0=91.77$.

Assuming equilibrium bidding on the part of the informed bidder, the uninformed bidder has an expected payoff of zero for any bid $b \in[25,125]$, and a negative expected payoff for any $b>125$. Hence, 125 is the break-even bidding threshold for the uninformed bidder, as bidding above it guarantees a negative expected payoff, when facing an informed bidder who bids according to equilibrium. ${ }^{13}$

\footnotetext{
${ }^{11}$ It would also be interesting to theoretically consider the case in which there are multiple informed bidders. However, Hendricks et al. (1987) and Hendricks and Porter (1988) find that, in the field, auctions with more than one informed bidder are relatively rare. They hypothesize that this is due to a bid rotation scheme on the part of informed firms. To the best of our knowledge this case has not yet been studied theoretically.

${ }^{12}$ Throughout the paper, decimal numbers are rounded off to two decimal places.

${ }^{13}$ Note that this would also be the break-even bidding threshold for all uninformed bidders in a game in where the number of uninformed bidders were increased.
} 
For the informed bidder, the expected value of the prize conditional on $z_{I}$ is the same as the expected value of the prize conditional on $z_{I}$ and having won the auction, regardless of the strategy employed by the uninformed bidder. ${ }^{14}$ This is because she observes the only signal. Thus, winning the auction does not imply that her signal exceeds any other signal (as is the case when more than one bidder is informed). Thus, the break-even bidding threshold for an informed ASYM bidder is

$$
E\left(X \mid Z_{I}=z_{I}\right)= \begin{cases}\frac{z_{I}+33}{2} & \text { if } z_{I} \in[17,33) \\ z_{I} & \text { if } z_{I} \in[33,217) \\ \frac{z_{I}+217}{2} & \text { if } z_{I} \in[217,233]\end{cases}
$$

\subsection{Symmetric and public information structure (SPUB)}

When neither bidder observes a signal the unique risk-neutral Nash equilibrium is for both bidders to bid $E(X)=125$. To see this, note that if either bidder were to bid above 125 , they would earn negative expected profits conditional on winning. For any bid $b<125$, the other bidder would have an incentive to bid $b+\epsilon<125$, and earn a positive expected profit. Hence, no bid below 125 is consistent with Nash equilibrium. ${ }^{15}$

The expected revenue generated by the auction is 125 and the expected profit of both bidders is equal to 0 . This implies that 125 is also the break-even bidding threshold.

Note that if the number of bidders were to increase, the unique symmetric equilibrium would be unchanged. ${ }^{16}$ Thus, any increase in the number of bidders would not affect the revenue or payoff predictions. Further, the break-even bidding strategy would be unchanged.

\subsection{Symmetric and private information structure (SPRIV)}

We now consider the case in which both bidders are informed. Information in this environment is ex-ante symmetric. ${ }^{17}$ The equilibrium of this game can be obtained by suitably specializing the results in Milgrom and Weber (1982). ${ }^{18}$ This gives the risk neutral Nash

\footnotetext{
${ }^{14}$ Note that this is also true if there are multiple uninformed bidders.

${ }^{15}$ Interestingly, this unique equilibrium involves all bidders playing a weakly dominated strategy. In particular, any bid below 125 weakly dominates a bid of 125 .

${ }^{16}$ In addition to the unique symmetric equilibrium there exist an infinite number of asymmetric equilibria in which two bidders bid 125, and the remaining bidders choose any strategy with support on [0,125].

${ }^{17}$ This information structure is used throughout much of the experimental literature on common-value auctions. See, e.g., Casari et al. (2007). Our setup differs in the parameter choice as well as in the number of bidders.

${ }^{18}$ Derivations of the symmetric risk-neutral Nash equilibrium bid function, as well as the corresponding revenue and payoffs predictions, are found in Appendix A. Similar derivations can be found in Kagel and
} 
equilibrium bid function to be

$$
\gamma\left(z_{i}\right)= \begin{cases}\frac{1}{3}\left(z_{i}+58\right) & \text { if } z_{i} \in[17,33) \\ z_{i}-8+g\left(z_{i}\right) & \text { if } z_{i} \in[33,217) \\ \frac{z_{i}}{3}+142+h\left(z_{i}\right) & \text { if } z_{i} \in[217,233]\end{cases}
$$

where $g\left(z_{i}\right)=\frac{16}{3} \exp \left[\frac{1}{8}\left(33-z_{i}\right)\right]$ is the nonlinear portion of the bid function when $z_{i} \in$ $[33,217)$, and $h\left(z_{i}\right)=\frac{4096}{3\left(z_{i}-201\right)^{2} \exp (23)}-\frac{4096}{3\left(z_{i}-201\right)^{2}}$ is the nonlinear part of the bid function when $z_{i} \in[217,233]$.

Notice that the equilibrium bid function is monotonically increasing. Further, bidders bid less than the expected value of the good conditional on their signal. This is due in part to bidders accounting for the fact that the bidder with the highest signal will win the auction. As such, in equilibrium each bidder uses their signal as a first order statistic when forming beliefs regarding the expected payoff of winning the auction. ${ }^{19}$

The ex-ante expected payoff of either bidder, and thus the corresponding information rent, is 2.50. The expected revenue of this auction is the expected value of the prize, less the expected payoffs of the bidders, which is equal to 120. Note that SPRIV auctions generate lower expected revenue that SPUB auctions due to the private information held by the bidders in the former. Also, in ASYM auctions the expected revenue is lower than in both symmetric information structures.

In an SPRIV auction, each bidder receives a signal regarding $x$. Since the equilibrium bid function is monotonically increasing in the signal, the break-even bidding threshold is equal to the expected value of the good conditional on having the highest signal. That is, bidder $i$ is bidding above the break-even bidding threshold when she bids more than

Levin (2002), and in Kagel and Richard (2001). Derivations of expected revenue and expected payoffs are also in Appendix A.

${ }^{19}$ If there are more than two bidders, then the resulting equilibrium bid function accounts for two things. First, the increase in the level of competition in the auction. Second, the fact that winning the auction means that the winning bidder's signal is the highest of a large number of signals. For a complete and thorough analysis, we refer the reader to Kagel and Richard (2001). On the interval [33,217], where most of our observations are, the equilibrium bid function is given by $z_{i}-8+\frac{16}{n+1} \exp \left(\frac{-n}{16}\left(z_{i}-33\right)\right)$. Note that the negative exponential term, which depends on $n$, decreases in magnitude as the signal increases. However, an increase in $n$ will, in expectation, increase the revenue generated by the auction, as well as decrease the expected payoffs of the bidders. 
$E\left(X \mid Z_{i}=z_{i}>Z_{j}\right) .{ }^{20}$ For each bidder, this threshold is

$$
E\left(X \mid Z_{i}=z_{i}>Z_{j}\right)= \begin{cases}\frac{1}{3}\left(z_{i}+58\right) & \text { if } z_{i} \in[17,33) \\ z_{i}-\frac{8}{3} & \text { if } z_{i} \in[33,217) \\ \frac{z_{i}\left(z_{i}+257\right)-92570}{3\left(z_{i}-201\right)} & \text { if } z_{i} \in[217,233]\end{cases}
$$

\section{Experimental design}

Participants are put into matching groups of 10 and randomly and anonymously matched into pairs. Each pair participates in a first-price, sealed-bid auction. Participants are randomly and anonymously re-matched after each round. This process is repeated for thirty rounds. ${ }^{21}$ We employ a $3 \times 1$ between-subject design which varies the information observed by bidders prior to placing their bids.

1. Asymmetric information structure ( $A S Y M)$ : Only one of the bidders is randomly chosen to observe a private signal. Since the informed bidder is randomly determined in each auction, bidders change roles throughout each session.

2. Symmetric and public information structure (SPUB): Neither bidder observes a private signal.

3. Symmetric and private information structure (SPRIV): Both bidders observe a private signal.

In each of these three treatments, the information structure is common knowledge. If a bidder is informed, she observes her signal before bids are placed. Bids are between zero and 225, inclusive, and are restricted to be multiples of 0.01. At the conclusion of each

\footnotetext{
${ }^{20}$ If there is an increase in the number of bidders, then the winning bidder will have the highest of a larger number of signals. As such, the break-even bidding threshold is decreasing in the number of signals.

${ }^{21}$ Since matching of participants occurred within groups of ten, and thirty rounds were conducted, participants were inevitably matched together more than once. However, participants were anonymously matched so that it would be difficult for subjects to build a reputation. Further, multiple sessions were usually run at the same time, so that there were twenty or thirty participants in the room, and participants were not informed that they would only interact within a group of ten. Botelho et al. (2009) shows, in the context of a public goods game, that when subjects are randomly re-matched such that they will be grouped with some subjects in multiple rounds they behave differently than if they never interact with any subject more than once. Thus, our random re-matching protocol may affect behavior. However, this matching protocol was used in all three treatments, so any effect is likely to be the same in all three information structures studied.
} 
auction each bidder observes both bids, the earnings of both bidders, their own balance and, if applicable, the signal(s). ${ }^{22}$

We examine two-bidder auctions for several reasons. First, in ASYM auctions, the equilibrium bid function of the informed bidder does not depend on the number of bidders. The expected payoffs of bidders in ASYM auctions (and hence, expected revenue) also does not depend on the number of bidders. Second, in SPUB auctions, symmetric Nash equilibrium bids and expected revenue are also invariant to the number of bidders. Third, SPRIV auctions have been extensively examined in the experimental literature, but we are unaware of any study which examines this information structure in a two-bidder context. Thus, our SPRIV treatment provides insight not already found in the literature. Fourth, the twobidder case is the simplest environment in which all the possible information structures can be studied. Lastly, as mentioned above, auctions with only two bidders are quite common in both wildcat and drainage auctions.

All sessions were run at the Economic Research Laboratory (ERL) at Texas A\&M University, and our participants were undergraduates of the institution. Sessions were run between September of 2008 and October of 2009. ${ }^{23}$ No subject had previously participated in an experiment on auctions. Five sessions were run for each of the three information structures, for a total of 150 subjects. The sessions were computerized using zTree (Fischbacher, 2007). The same draws of values and (when applicable) signals, were used in every session. Participants were separated by dividers such that they could not interact outside of the computerized interface. They were provided with instructions, which were read aloud by an experimenter. ${ }^{24}$ After the instructions were read, questions were answered privately. Each participant then individually answered a set of questions to ensure understanding of the experimental procedure; their answers were checked by an experimenter who also answered any remaining questions. ${ }^{25}$ Participants were provided with a history sheet which allowed them to keep track of bids, earnings and, if applicable, signal(s) in each round. Each session lasted approximately two hours. Each participant began with a starting balance of $\$ 20$ to

\footnotetext{
${ }^{22}$ This level of ex-post observation has been widely used throughout the literature. Armantier (2004) finds that the ex-post observation of bids, earnings and signals "homogenizes behavior, and accelerates learning toward the Nash equilibrium" in common-value, first-price auctions with the SPRIV information structure. Note that because bidder earnings are observed, bidders are able to also determine the realized value of the prize.

${ }^{23}$ The sessions for the ASYM and SPRIV treatments were run during September and October of 2008. The SPUB sessions were run the following October.

${ }^{24}$ The instructions for the ASYM treatment are found in Appendix B. Instructions for the remaining treatments are available upon request.

${ }^{25}$ We did not begin the experiment until each subject correctly answered all these questions. We did not collect data on which subjects initially answered some questions incorrectly.
} 
cover any losses, although no participant went bankrupt. At the end of all thirty rounds, each participant was paid their starting balance plus their cumulative earnings, as well as a show-up fee of $\$ 5$. The bids, signals and values were all denominated in Experimental Dollars (ED), which were exchanged for cash at a rate of $160 \mathrm{ED} / \$ 1$. The average payoff was $\$ 26.91$, with a range between $\$ 23.31$ and $\$ 32.33$.

\section{Results}

\subsection{Bidding behavior}

Since subjects interact in groups of ten within a session, and are randomly rematched throughout the thirty periods of the experiment, behavior within a given session is not independent. To ensure that our analysis relies on independent observations we use session level data in our non-parametric tests. Thus, we have five independent observations for each of the three information structures we study. Unless specifically noted, results of a given test are robust to restricting attention to the first or last third of the experiment.

There are four bidder types in our experiment. Table 1 contains summary statistics for observed and predicted bidding behavior for each of these types, aggregated across all rounds and sessions. For informed bidders, predicted bids are calculated using the realized signals, rather than the ex-ante bid predictions.

Informed ASYM bidding is illustrated in Figure 1, which contains a scatter plot of bids and the equilibrium bid function. Informed bidders in ASYM auctions overbid on average. While in the first third of the experiment this is statistically significant (Wilcoxon signedrank test, $z=2.02, p=0.02$ ), it is consistent with Nash predictions by the last third of the experiment (Wilcoxon signed-rank test, $z=0.14$, n.s.). ${ }^{26}$ This convergence to theoretical predictions is further illustrated in Figure 2, which shows boxplots of bidding by period. This figure also highlights that variation in overbidding decreases as bidders gain experience.

Informed bids are, on average, moving closer to Nash equilibrium predictions as participants gain experience. However, if uninformed bidders are not bidding according to their equilibrium bidding strategy, then equilibrium predictions are not a valid benchmark for informed bidders. Referring to Table 1, note that uninformed bidders bid on average a full $23 \%$ below the expected value of their predicted strategy. Further, non-parametric tests show that the observed and predicted bid distributions of the uninformed bidders are not

\footnotetext{
${ }^{26}$ When a test is not significant at conventional levels, we indicate this with the abbreviation $n . s .$.
} 
equal (Kolmogorov-Smirnov test, $D=0.63, p<0.01)$ ). ${ }^{27}$ Thus, uninformed ASYM bidders are underbidding relative to Nash predictions.

This point is further illustrated in Figure 3, which compares the equilibrium distribution of bids against the empirical distributions of both informed and uninformed bids. In the first panel, all periods are considered. In the second and third panels attention is restricted to the first and last ten periods, respectively. Note that even in the last third of the experiment the distribution of uninformed ASYM bids is almost entirely to the left of equilibrium predictions. $^{28}$ Indeed, even in the last third of the experiment, when the distribution of bids of the informed players is closer to that of the uninformed bidders, they are still statistically different (Kolmogorov-Smirnov test, $D=0.24, p<0.01){ }^{29}$

The fact that uninformed ASYM bidders bid less than informed ASYM bidders suggests that the informed bidders may be able to profitably reduce their bids. To investigate this possibility we calculate the best response of the informed ASYM bidders to the empirical distribution of the uninformed ASYM bids. ${ }^{30}$ We find that observed bids of informed ASYM bidders exceed their best response (Wilcoxon signed-rank test, $z=2.02, p=0.02$ ), and that their observed payoff is less than their best response payoff as a result (Wilcoxon signed-rank test, $z=2.02, p=0.02$ ). This is illustrated in Figure 4, which contains a scatterplot of the difference between the observed bids of the informed ASYM bidders and the corresponding best response, as well as a scatterplot of the difference between the observed payoffs of the informed ASYM bidders and the corresponding best response payoff. Clearly, informed bidders could profitably shade their bids more than is observed. ${ }^{31}$ In fact, the average

${ }^{27}$ This test uses individual bids as the unit of observation, as the Kolmogorov-Smirnov test requires a relatively large number of observations to properly evaluate the null hypothesis. Using session level data, we find that uninformed ASYM bids are, on average, lower than predicted (Wilcoxon signed-rank test, $z=1.75$, $p=0.04)$.

${ }^{28}$ While it is clear that uninformed ASYM bids do not conform to the mixed strategy prediction, it is worth asking whether such bidders are mixing at all. We find strong evidence to the contrary. Participants tend to choose the same bid in consecutive instances of being uninformed. Further, participants chose their modal uninformed bid an average of $29 \%$ of the periods in which they are uninformed. Additionally, $82 \%$ of uninformed ASYM bids are integers, and $59.47 \%$ are multiples of five.

${ }^{29}$ As above, this test uses individual bids as the unit of observation. As a robustness check, we also report the results of a signed-rank test on session level data, which is consistent with the finding that informed ASYM bids exceed those of uninformed ASYM bidders. The results do not differ when considering all periods, the first ten periods, or the last ten periods (Wilcoxon signed-rank test, $z=2.02, p=0.02$ ).

${ }^{30}$ When calculating this best response, we assume that ties are broken randomly, with both bidders having a $50 \%$ chance of winning.

${ }^{31}$ The fact that informed ASYM bidders do not best respond to the empirical distribution of ASYM could be due to the random re-matching protocol we use in our experiments. It would be interesting to study the same information structure in an environment with a fixed matching protocol or a perfect strangers matching protocol to investigate this question. 
difference between the observed and best response bids of the informed bidders is 10.50, which is "money left on the table."

Thus far, our experiment finds that uninformed ASYM bidders bid cautiously, although the underlying reasons are unclear. One possibility is that this is in response to the informational disadvantage they face. The bidding behavior in SPUB auctions allows us to evaluate whether removing their strategic disadvantage would result in more aggressive bidding. In the first ten periods we cannot reject that SPUB and uninformed ASYM bids are equal (Robust rank order test, $U^{\prime}=1.32$, n.s.). However, by the last ten periods, bidders in SPUB auctions bid more than uninformed ASYM bidders (Robust rank order test, $U^{\prime}=n . d$, $p<0.01){ }^{32}$ In fact, we cannot reject that bidders in SPUB auctions bid, on average, the same as informed ASYM bidders (Robust rank order test, $U^{\prime}=1.19$, n.s.). ${ }^{33}$

It is important to note that, despite bidding more than uninformed ASYM bidders in the last third, SPUB bidders underbid relative to Nash predictions. Further, this underbidding is highly significant (Wilcoxon signed-rank test, $z=6.15, p<0.01$ ). Figure 5 further illustrates this point by showing boxplots of SPUB bids relative to Nash predictions over all periods. Note that while underbidding decreases slightly in early periods, it persists throughout the entire experiment. Further, the magnitude of this underbidding remains dramatic throughout. Clearly, underbidding by uninformed bidders is robust to changes in the information structure.

As far as we know, this is the first observed underbidding in single-unit, common-value auctions. While such behavior is not so surprising in ASYM auctions where the uninformed bidder is significantly disadvantaged, underbidding in SPUB auctions is puzzling since a bidder could raise her bid, and obtain a large payoff on average. One concern is that the observed underbidding is driven by a subset of subjects who bid close to zero in order to withdraw from the auction. To investigate this, we calculate the average uninformed bid of each bidder. The number of bidders with an average uninformed bid less than twenty-five is only one in SPUB auctions, and only four in ASYM auctions. Figure 6 further illustrates individual level bidding by uninformed bidders by presenting boxplots of bids, where each box summarizes all the bids on an individual bidder. Note that while there is heterogeneity

\footnotetext{
${ }^{32}$ In the last ten periods, at the session level, the lowest average of SPUB bids is higher than the highest average of uninformed ASYM bids. As such, the test statistic of the Robust rank order statistic is not defined and $p<0.01$. We will denote the test statistic by $n . d$. in such cases. Critical values for the Robust rank order test can be found in Feltovich (2003).

${ }^{33}$ In the first ten periods SPUB bidders bid less than informed ASYM bidders (Robust rank order test, $U^{\prime}=7.19, p<0.01$ ). However, by the last ten periods their bids do not differ (Robust rank order test, $\dot{U}=1.14$, n.s.).
} 
in bidding, the average underbidding we observe is not driven by a subset of subjects who bid at or close to zero.

The literature on common-value auctions typically finds that when all bidders are privately informed they bid above the break-even bidding threshold such that they obtain negative profits in expectation (the winner's curse). Such behavior is found both when the information structure is asymmetric in the sense that one bidder obtains a more informative signal than the others (Kagel and Levin, 1999; Harrison and List, 2008) and when bidders are in an SPRIV information structure (Kagel and Levin, 2002).

The data from our SPRIV treatment thus provides a valuable basis for comparison with the existing literature. ${ }^{34}$ Do we observe overbidding by bidders in SPRIV auctions? Do these bidders fall victim to the winner's curse? Figure 7 provides some insight by comparing observed bids with the equilibrium bid function. Bidders overbid (Wilcoxon signed-rank test, $z=1.75, p=0.04) .{ }^{35}$ In fact, bidders in the SPRIV treatment bid more than any other type we study. ${ }^{36}$ However, notice that the magnitude of deviations from Nash predictions is small. This is a result of the signal structure. Since a signal can be at most eight experimental units away from the true value, bidders easily ascertain that bidding more than eight above their signal will result in negative earnings conditional on winning. Likewise, bidding more than eight below their signal lowers the probability of winning. As such, $74 \%$ of bids in the SPRIV treatment fall within eight experimental units of the signal. Figure 8 illustrates how overbidding in SPRIV auctions changes over time. Of note is that even in the last periods of the experiment, overbidding is prevalent.

Figure 8 illustrates that SPRIV bidders persistently overbid, but do they bid above the break-even bidding threshold? Table 2 provides a breakdown of the relevant frequencies for each type of bidder. Frequencies for all bidders and for winning bidders are reported. Figure 9 illustrates how these frequencies change over time. Not only do SPRIV bidders often bid in excess of the break-even threshold, they are the only type of bidder who do so with non-trivial frequency in later periods.

\footnotetext{
${ }^{34}$ This comparison is possible because the only difference between the treatments is the information structure itself. However, it is possible that features of our design that are constant across all treatments drive our results. Varying such features in a systematic way would provide valuable robustness checks, which we leave for future research. For example, investigating the extent to which the random re-matching protocol we use in our experimental design drives our results would be an interesting avenue for future research.

${ }^{35}$ If we restrict attention to the final ten periods, we cannot reject that SPRIV bids align with Nash predictions (Robust rank order test, $\dot{U}=1.48, n . s$. ).

${ }^{36}$ For all comparisons, the lowest session average of bids in an SPRIV auction was higher than the highest session average of the type being compared. As such, the test statistic of the Robust rank order statistic is undefined and $p<0.01$.
} 
However, it is worth noting that the frequency with which SPRIV bidders bid in excess of the break-even bidding threshold is lower than in other studies. This difference may be attributable to the fact that we examine auctions with two bidders, while the rest of the literature has examined environments with a larger number of bidders. ${ }^{37}$ As the number of bidders increases the adverse selection problem increases; in order to win the auction a bidder's signal must be the largest of a larger number of signals, driving the break-even bidding strategy down. Further, bidders tend to bid more aggressively when there is a larger number of bidders. ${ }^{38}$

To further understand the determinants of bidding behavior we estimate bid functions using random effects tobits to control for correlation of participant behavior over time, and the fact that bids were restricted to be within the interval [0,225]. We restrict our attention to observations in which the observed signal (or the signal that a bidder would have observed had she been informed) is in the interval $[33,217)$, where the majority of our observations lie, as is typical in the literature. ${ }^{39}$ We include $z_{i t}$, the (possibly unobserved) signal of bidder $i$ in period $t .^{40}$ When the equilibrium bid function for the relevant treatment is nonlinear, we also control for the nonlinear portion. In the case of SPRIV auctions this nonlinear portion is $g\left(z_{i t}\right)$. For informed bidders in ASYM auctions, this nonlinear portion is $m\left(z_{i t}\right)$. We also control for gender $\left(M_{i}=1\right.$ if the participant is a male, and zero otherwise), and bidder experience $(\ln (1+t))$. When jointly estimating bid functions $S P R I V_{i}, A I N F_{i}$ and $A U N F_{i}$ are dummies for bidders in SPRIV auctions, informed bidders in ASYM auctions and uninformed bidders in ASYM auctions, respectively.

Table 3 contains the estimates. As expected, the coefficient corresponding to the (unobserved) signal is not significant for both SPUB and uninformed ASYM bidders. Conversely, the coefficient for the (observed) signal is highly significant in the estimated bid function for bidders in SPRIV auctions. Indeed, this coefficient is not significantly different than one. Further, the nonlinear part of the bid function $\left(g\left(z_{i t}\right)\right)$ is not significant. A similar result is found for informed bidders in ASYM auctions: the coefficient of the signal is positive and highly significant and the nonlinear portion of the bid function $\left(m\left(z_{i t}\right)\right)$ is not significant. Note that the magnitude of the coefficient on $z_{i t}$ for informed ASYM bidders is significantly less than one, indicating that while such bidders are not bidding according to the equilibrium

\footnotetext{
${ }^{37} n \in\{4,6,7\}$ are typical. Frequently, $n$ is varied. See e.g., Kagel and Levin (1986).

${ }^{38}$ This behavior has been observed in many studies. See Kagel and Levin (2002).

${ }^{39}$ See e.g., Casari et al. (2007).

${ }^{40}$ The realized value of the good and the two signals are held constant across treatments. In some treatments the bidder does not observe "her" signal. Thus, when a bidder is uninformed, there is a (unobserved) signal assigned to her. We are interested in testing whether or not the signal is significant when it is not observed.
} 
bid function, they do reduce their bids relative to the signal to (seemingly) account for the cautious bidding of uninformed ASYM bidders.

Interestingly, the results regarding bidder experience $(\ln (1+t))$ differ substantially across treatments. In SPUB auctions, the coefficient is positive and significant. This indicates that SPUB bidders are learning to bid closer to equilibrium as they gain experience. In the ASYM treatment the coefficients for both informed and uninformed bidders are negative and significant; they are reducing their bids as they gain experience. In the case of SPRIV bidders, learning is not significantly different from zero.

Interestingly, we also find that gender effects only exist when a bidder is informed. In particular, males bid significantly less than females when they are informed. However, uninformed ASYM bidders and SPUB bidders do not exhibit gender differences in bidding.

\subsection{Payoffs}

Table 4 reports summary statistics for bidder payoffs. The average predicted payoff of informed bidders in ASYM and SPRIV auctions was calculated using the signals observed by participants, rather than the ex-ante expected payoffs to maximize comparability.

Note that uninformed bidders in ASYM auctions are losing money on average, although payoffs are not significantly different than the prediction of zero (Wilcoxon signed-rank test, $z=0.94$, n.s.). ${ }^{41}$ Given this, one might expect that these bidders would simply bid zero. However, the strategic implications of such a bid make this outcome unlikely. If the uninformed bidder bids zero, then the informed bidder can win with certainty by bidding an arbitrarily small amount. Given this, the uninformed bidder's best response would be to bid marginally more than this, and so on. This intuition is borne out by our data: $96.4 \%$ of uninformed ASYM bidders bid positive amounts. It is important to note that Hendricks et al. (1987) and Hendricks and Porter (1988) report that the uninformed bidders in drainage auctions earned profits of approximately zero, which is in line with our data.

Are informed bidders better off for having observed a signal? Equivalently, are informed bidders earning an information rent? For informed bidders in ASYM auctions the answer is yes; they earn more than bidders in SPUB auctions (Robust rank order test, $U^{\prime}=7.19, p<$ 0.01). This is despite the observed underbidding in SPUB auctions. For bidders in SPRIV

\footnotetext{
${ }^{41}$ In the first ten periods, uninformed ASYM bidders have negative payoffs on average (Wilcoxon signedrank test, $z=1.75, p=0.04$ ). However, by the last ten periods they earn their predicted payoff of zero (Wilcoxon signed-rank test, $z=0.14$, n.s.).
} 
auctions the answer is no; we are unable to reject equality of payoffs between bidders in SPRIV bidders and uninformed bidders in ASYM auctions (Robust rank order test, $U^{\prime}=1.14$, n.s.). ${ }^{42}$ This is largely due to the presence of the winner's curse in SPRIV auctions, which lowers their payoff relative to predictions (Wilcoxon signed-rank test, $z=1.75, p=0.04$ ). ${ }^{43}$ It may be noted that the standard deviation of payoffs for a bidder in SPRIV auctions is much lower than that of an uninformed bidder in ASYM auctions, owing largely to the relatively high level of precision of the signals.

Perhaps not surprisingly, and in accordance with theory, informed bidders in ASYM auctions earn more than their uninformed counterparts (Wilcoxon signed-rank test, $z=2.02$, $p=0.02$ ). Likewise they earn more than bidders in SPRIV auctions (Robust rank order test, $\left.U^{\prime}=n . d ., p<0.01\right)$. Further, we are unable to reject that informed bidders in ASYM auctions earn their predicted payoff (Wilcoxon signed-rank test, $z=0.41$, n.s.). ${ }^{44}$ This is not surprising, since informed bidding in ASYM auctions does not dramatically deviate from predictions, and these bidders do not shade their bids as much as the underbidding of uninformed ASYM bidders would permit.

When considering SPUB bidders, however, theory falls far short. Due to the dramatic underbidding of SPUB bidders, they earn more than predicted (Wilcoxon signed-rank test, $z=2.02, p=0.02$ ). In addition, not only do they do better than uninformed bidders in ASYM auctions (Robust rank order test, $U^{\prime}=n . d ., p<0.01$ ), but they also earn more than bidders in SPRIV auctions (Robust rank order test, $U^{\prime}=n . d ., p<0.01$ ). That is, in symmetric information structures, bidders are better off in ignorance!

\subsection{Revenue}

Table 5 reports summary statistics of revenue. Predicted revenue is calculated using the realized signals, when applicable. Theory predicts that the asymmetric information structure will reduce revenue regardless of which symmetric information structure serves as a baseline. $^{45}$

\footnotetext{
${ }^{42}$ If attention is restricted to the first ten periods, then SPRIV bidders earn more than uninformed ASYM bidders (Robust rank order test, $U^{\prime}=2.06, p=0.05$ ).

${ }^{43}$ By the final ten periods, the prevalence of the winner's curse has reduced, such that we cannot reject that SPRIV payoffs are in line with theory (Wilcoxon signed-rank test, $z=0.67$, n.s.).

${ }^{44}$ This result is largely driven by the fact that in the first ten rounds informed ASYM bidders earn less than predicted (Wilcoxon signed-rank test, $z=1.75, p=0.04$ ), while in the last ten periods they earn more (Wilcoxon signed-rank test, $z=1.48, p=0.07$ ).

${ }^{45}$ Having some bidders be better informed than others is not always predicted to decrease revenue. Campbell and Levin (2000) provide an example in a discrete environment where the presence of a better informed bidder can increase revenue relative to a case where less informed bidders have identically distributed private
} 
Our experiment suggests this is not the case. We find strong support for the prediction that SPRIV auctions revenue dominate ASYM auctions (Robust rank order test, $U^{\prime}=n . d$., $p<0.01)$. This is driven by the fact that revenue in SPRIV auctions is higher than predicted (Wilcoxon signed-rank test, $z=2.02, p=0.02$ ). Furthermore, we cannot reject the hypothesis that revenue in ASYM auctions is equal to predictions (Wilcoxon signed-rank test, $z=0.14, p=0.89) .{ }^{46}$

However, the underbidding we observe in SPUB auctions dramatically reduces its revenue relative to theory (Wilcoxon signed-rank test, $z=2.02, p=0.02$ ) such that we are unable to reject revenue equivalence between SPUB and ASYM auctions (Robust rank order test, $U^{\prime}=0.47$, n.s. $) .{ }^{47}$ Further, the underbidding in SPUB auctions, combined with the winner's curse in SPRIV auctions flips the revenue ranking between the two symmetric information structures. Revenue is higher in SPRIV auctions (Robust rank order test, $\dot{U}=n . d ., p<$ $0.01)$.

\section{SPUB auctions with more than two bidders}

As discussed above, our experimental design focuses on two-bidder environments in large part because it is the simplest possible setup that allows us to examine all the possible combinations of informed and uninformed bidders. We have shown that bids in SPUB auctions with two bidders are dramatically below predictions, and that bidders rarely fall victim to the winner's curse.

This surprising result suggests two questions. First, are these results replicable? Second, are these results a consequence of restricting attention to two-bidder environments? To address these issues, we ran several additional sessions, which vary the number of bidders in common-value auctions with an SPUB information structure.

In particular, we ran five sessions of SPUB auctions with two bidders, five sessions with four bidders, and five sessions with six bidders. In all of these sessions there were exactly

signals. Kagel and Levin (1999) find that the presence of a better informed bidder increases revenue relative to an SPRIV information structure when less informed bidders observe conditionally independent signals and the better informed bidder observes the realized value. Both Kagel and Levin (1999) and Harrison and List (2008) find support for this prediction in experimental settings where values are induced and thus observed by the experimenters.

${ }^{46}$ This is driven by the fact that in the first ten periods ASYM auctions generate more revenue than predicted (Wilcoxon signed-rank test, $z=1.75, p=0.04$ ), while the opposite is true in the last ten periods (Wilcoxon signed-rank test, $z=1.75, p=0.04$ ).

${ }^{47}$ In the first ten periods ASYM auctions generate more revenue than SPUB auctions (Robust rank order test, $U^{\prime}=7.19, p<0.01$ ), but there is no significant revenue difference by the last ten periods (Robust rank order test, $\dot{U}=0.92$, n.s.). 
three auctions run simultaneously in any given period. Thus, there were six subjects in twobidder sessions, twelve subjects in four-bidder sessions, and eighteen subjects in six-bidder sessions. We used the same draws of the value of the good across all of these sessions. ${ }^{48}$ That is, in each period there are three draws which correspond to the value of the good in each of the three auctions in that period. All of these sessions were run at Centro Vernon Smith de Economía Experimental at Universidad Francisco Marroquín in October and November of 2016. All other features of these sessions are the same as in the SPUB sessions we initially ran at Texas A\&M University.

Table 6 reports summary statistics of both the bids and the payoffs of the winning bidders in these sessions. We replicate the finding that there is underbidding in SPUB auctions with two bidders (Wilcoxon signed-rank test, $z=2.02, p=0.02$ ). As a result, the payoffs of winning bidders in such auctions are also greater than predicted (Wilcoxon signed-rank test, $z=2.02, p=0.02$ ). Table 7 shows the frequency of bids above the break-even bidding threshold, both for all bidders and winning bidders. Note that we also replicate the finding that bids above the break-even bidding threshold are not common when there are two bidders.

Interestingly, when the number of bidders is increased to four there is still underbidding on average (Wilcoxon signed-rank test, $z=2.02, p=0.02$ ), such that the payoffs continue to be greater than predicted (Wilcoxon signed-rank test, $z=1.75, p=0.04$ ). However, note that bids have increased relative to the two-bidder case (Robust rank order test, $U^{\prime}=3.16$, $p<0.05$ ). As a result payoffs have fallen relative to the two-bidder case (Robust rank order test, $\left.U^{\prime}=n . d, p<0.01\right)$. Further, note that the frequency of bids above the break-even bidding threshold has also increased relative to the two-bidder case (Robust rank order test, $\left.\dot{U}^{\prime}=6.095, p<0.03\right)$.

When the number of bidders is increased to six, bids continue to be, on average, less than predicted (Wilcoxon signed-rank test, $z=2.02, p=0.02$ ). However, bids are higher than in both the two-bidder case (Robust rank order test, $U^{\prime}=n . d ., p<0.01$ ) and the four-bidder case (Robust rank order test, $\dot{U}^{\prime}=4.20, p<0.03$ ). Indeed, the frequency with which bids exceed the break-even bidding threshold results in lower payoffs than predicted (Wilcoxon signed-rank test, $z=2.02, p=0.02$ ). That is, payoffs in the six-bidder case are negative. ${ }^{49}$

\footnotetext{
${ }^{48}$ There were thirty subjects who participated in sessions with two-bidder auctions, sixty subjects who participated in sessions with four-bidder auctions and ninety subjects who participated in sessions with six-bidder auctions.

${ }^{49}$ Not surprisingly, payoffs in the six-bidder case are significantly lower than in both the two-bidder case (Robust rank order test, $\dot{U}=n . d, p<0.01$ ) and the four-bidder case (Robust rank order test, $\dot{U}=n . d$,
} 
To summarize, average bids are monotonically increasing in the number of bidders. This is illustrated in Figure 10, which contains line graphs of average bids in each of these three group sizes by period. Note that the average bid is less than the unique symmetric Nash bid in all cases. As a result of bids increasing in the number of bidders, average payoffs of bidders are monotonically decreasing in the number of bidders. This is illustrated in Figure 12 , which shows the average payoff of winning bidders by period. ${ }^{50}$ The fact that the payoffs of winning bidders become negative when there are six bidders is driven by the frequency with which bids exceed the break-even bidding threshold, as illustrated in Figure 9.

The fact that average bids are increasing in the number of bidders is similar to the results from the literature similar to our SPRIV treatment. ${ }^{51}$ In our view, investigating whether bids are increasing in the number of bidders in other environments is an interesting avenue for future research, especially in information structures similar to our ASYM treatment.

\section{Alternative bidding models}

Our most surprising result is the persistent and dramatic underbidding by uninformed bidders. In order to explain the non-equilibrium behavior we observe, any explanation must simultaneously account for underbidding by uninformed bidders in ASYM and SPUB auctions and overbidding in SPRIV auctions. In what follows, we assess the ability of several alternative bidding models to explain our data.

One possibility is collusion. In particular, when $n \in\{2,4\}$, SPUB bidders had positive payoffs, and may have been explicitly or implicitly colluding. However, since participants were separated by dividers, were monitored by experimenters to prevent communication, and were randomly and anonymously re-matched every period, this seems unlikely. Further, if bidders were able to collude in some treatments we would expect to see similar collusion in the other treatments. Since colluding bidders in SPRIV auctions would not overbid, collusion is unable to explain the data.

A potential explanation for our data is that bidders are not risk neutral, as assumed in the theory. To explore if violations of risk neutrality can explain our data, we consider symmetric equilibria in SPUB auctions assuming that preferences are homogeneous and

$p<0.01)$. Likewise, the frequency of bids in excess of the break-even bidding threshold is greater in the six-bidder case than in the two-bidder case (Robust rank order test, $U^{\prime}=n . d ., p<0.01$ ) or the four-bidder case (Robust rank order test, $U^{-}=6.574, p<0.03$ ).

${ }^{50}$ Since the number of bidders is varied, focusing on the average payoff of all bidders would give misleading results, as each losing bidder obtains a payoff of zero.

${ }^{51}$ See e.g., Kagel and Levin (1986). 
common knowledge. Since losses are possible in this environment, we need a utility function that is defined over both gains and losses. For simplicity we use the following

$$
u(x)= \begin{cases}x^{\alpha} & x \geq 0 \\ -\lambda x^{\beta} & x<0\end{cases}
$$

For the sake of brevity, we relegate a detailed discussion of equilibrium under risk to Appendix C. Interestingly, the bid predicted by the symmetric Nash equilibrium does not depend on the number of bidders. Since we observe that, on average, SPUB bids increase in the number of bidders, our data is not able to be explained by this model. Nonetheless, we calculate equilibrium predictions under several assumptions about $\alpha, \lambda$ and $\beta$. First, we consider the case where $\alpha=\beta$ and $\lambda=1$. In this case, bidders are not loss averse, and the curvature of the utility function is the same over gains and losses. In this case, the unique symmetric equilibrium is the same as in the risk neutral case. Next, we consider the case where bidders are loss averse. Using the utility function parameters estimated by Harrison and Rutström (2009), we find the symmetric equilibrium bid in this case to be $115.70 .{ }^{52}$ Since observed bids are well below this when $n=2$, we again conclude that risk and loss aversion are not able to explain bidding behavior in SPUB auctions.

A prominent explanation for the winner's curse is the notion of a cursed equilibrium (Eyster and Rabin, 2005), in which boundedly rational bidders are assumed to incorrectly believe that with some probability the other bidders will ignore their private information and bid the average of their type contingent strategy. In such an equilibrium, bidders believe that winning the auction need not be bad news regarding the value, and consequently do not shade their bids as aggressively as predicted by the Nash equilibrium. However, cursed equilibrium only differs from Nash equilibrium when (at least some) bidders hold private information. As such, it is unable to explain underbidding by players in SPUB auctions.

Next we consider whether a level- $k$ model of reasoning can explain observed behavior. Level- $k$ models have previously been applied to auctions by (Crawford and Iriberri, 2007). In such models, each bidder is associated with a level of reasoning. Level zero bidders are assumed to bid naively (often this is assumed to be uniform randomization), level one bidders best respond to their (presumably incorrect) beliefs that all other bidders are level zero, level two bidders best respond to their beliefs that all other bidders are level one, and so on. The key assumption of such models is that all types are overconfident in the sense that they believe all other bidders to be one level below their own.

\footnotetext{
${ }^{52}$ In Appendix $\mathrm{C}$ we also consider the case of risk and loss aversion and nonlinear probability weighting. Adding nonlinear probability weighting only changes the equilibrium bid slightly.
} 
In an SPUB auction a level one bidder believes that level zero bidders are uniformly randomizing on [25,225]. When $n=2$, a level one bidder best responds with a bid of 75 . In an SPUB auction with $n=4$, a level one bidder best responds with a bid of 100 and when $n=6$ a level one bidder best responds with a bid of 108.33. A level two bidder best responds to her belief that all other bidders are level one by bidding 0.01 above the bid of a level one bidder. ${ }^{53}$ Level three bidders bid 0.01 above that of level two bidders, and so on. Comparing these predictions with the observed SPUB data summarized in Table 6, it is clear that a level- $k$ model of reasoning is, on the surface, qualitatively in line with our SPUB data. In particular, it is able to account for both the observed underbidding, as well as the fact that this underbidding decreases as the number of bidders increase.

To investigate the ability of such a model to explain our data further, we estimate the proportion of levels in our SPUB data, using maximum likelihood. Following Crawford and Iriberri (2007), we assume that bidders are no higher than level two. We allow the proportions of levels to vary with the number of bidders in the auction. For a detailed discussion of our estimation procedure and results, please see Appendix D. In a model in which level zero bidders are excluded, the estimation finds that well over $90 \%$ of bidders are level one, regardless of the number of bidders. However, none of the estimated proportions of level one or level two bidders are statistically significantly different from zero. In a model which includes level zero bidders, the Hessian is non-invertible, such that the standard errors are not computable. The point estimates suggest that there is a relatively small proportion of bidders who are level zero, with the remaining bidders being level one; the proportion of level two bidders was zero, regardless of the number of bidders. However, since the standard errors are not available, we are unable to conclude that these estimates are meaningful.

The difficulty in estimating the proportions of each level of bidder may be driven by the fact that is quite difficult to distinguish between level one bidders and level two bidders, as the corresponding bid predictions are extremely close. In our view, a promising avenue for future research is a SPUB environment with a more coarsely discretized bid space, such that levels are more easily distinguished.

\section{Discussion}

One of the most celebrated and robust results in the experimental literature on commonvalue auctions is the winner's curse. It has been found to be robust to changes in information

\footnotetext{
${ }^{53}$ This assumes that the bid space is discretized to two decimal places. If the bid space is a continuum, the best response to these beliefs does not exist.
} 
structure (Kagel and Levin, 1999), publicly providing an additional signal to all bidders (Kagel and Levin, 1986), among others. However, common to all these studies is that all bidders observe private information.

When noting strong evidence for equilibrium bidding behavior in drainage auctions, Hendricks et al. (1989) note that: "These results raise some questions about experimental work on the bidding behavior in common value auctions. All of the studies that we are familiar with report that bidders suffer from the 'winner's curse.' Whether this is due to the inexperience of the subjects, the relatively small stakes, or structural features of the auction are issues worth pursuing." Our findings suggest that the structural feature responsible for the widespread observation of the winner's curse may be the fact that all bidders have private information in the existing literature.

This raises important questions regarding how to determine whether or not bidders hold private information in the field. Given that the behavior of informed and uninformed bidders differs so significantly, making the correct assumption is important. This issue is not clear cut, as in the literature we observe instances in which bidders who have access to the same type of information are sometimes assumed to be informed, and other times uninformed. For example, non-neighbor firms in drainage auctions and bidders in wildcat auctions only have access to public seismic information for the plot to be leased prior to bidding. Non-neighbor firms are assumed to be uninformed in Hendricks et al. (1987), Hendricks and Porter (1988), Hendricks et al. (1989) and Hendricks et al. (1994), and these papers find considerable support for this assumption. However, when analyzing wildcat auctions Hendricks et al. (1987) and Hendricks et al. (2003) assume that all bidders are privately informed. Another example can be found in Harrison and List (2008) who report the results of a field experiment regarding bidding for packs of sports cards. Although bidders only handled the same unopened pack of cards prior to bidding, they were assumed to be privately informed.

In the real world situations arguably involving only public information regarding the value of the good arise frequently. Bidders have private estimates of the value, but had access to the same information about the value when forming these estimates. For example, if a book proposal is distributed among various publishers, who may subsequently make offers, it is reasonable to think that all publishers have access to the same information (assuming for the sake of argument that they have no information beyond the proposal itself). If their estimates differ, they must use different methods to form them. Given that our results suggest that behavior differs significantly between informed and uninformed bidders, making the correct assumption when formulating policy recommendations is crucial. Do bidders in fact hold 
private information on which they condition their bids, or do they each use the same public information to form possibly different beliefs?

In practice, whether or not bids are meaningfully correlated with the ex-post value may offer some guidance. If bidders are uninformed, then they are only able to condition their bids on the expected value conditional on available public information. They have no way of further relating their bids to the realized value. Thus, if bids are uncorrelated with the value, it is reasonable to assume that bidders are uninformed. An important example is found in Hendricks and Porter (1988) which finds that the bids of non-neighbor firms in drainage auctions are uncorrelated with the ex-post value of the lease.

Turning now to information rents, recall that theory predicts that both uninformed bidders in ASYM and SPUB auctions will earn an expected profit of zero. Thus, the information rent of an informed bidder in an ASYM auction is, in theory, a consequence of a reduction in revenue relative to the SPUB case. ${ }^{54}$ However, since we are unable to reject revenue equivalence between the SPUB and ASYM information structures, we find that the informed ASYM information rent is derived at the expense of the other bidder, rather than from the seller.

Our results regarding payoffs have interesting implications for a modified game in which both bidders simultaneously decide whether or not to purchase a signal prior to the auction. Theory predicts that acquiring a signal is strictly dominant, provided the cost is less than the ex-ante expected payoff of an SPRIV bidder. Consequently, we would expect an SPRIV information structure in the subsequent auction. However, since we do not observe a significant difference in the payoffs of SPRIV and uninformed ASYM bidders, our data suggests that even a small cost of acquiring a signal would change the predicted information structure. In particular, taking observed payoffs in the three information structures as given, there are two equilibria in the information acquisition stage which correspond to both possible ASYM information structures. In our view, experimental analysis of this information acquisition game would be an interesting avenue for future research.

It is noteworthy that, contrary to predictions, increasing the degree of competition in auctions with an SPUB information structure affects both the bids and payoffs of participants. Our data suggests that there may be a threshold number of bidders above which bids become aggressive enough that payoffs become negative. However, the number of bidders observed in the field is often low. Revisiting the data used by Hendricks, Porter and co-authors, we

\footnotetext{
${ }^{54}$ This follows from the fact that a common-value auction without a reservation price is a zero-sum game between the bidders and the seller.
} 
find that an overwhelming majority of auctions attracted less than seven bidders. In fact, auctions with only four or less bidders account for $89 \%$ of drainage auctions and $73 \%$ of wildcat auctions. Given this, one would expect to see underbidding and positive payoffs in the corresponding auctions. The relatively low number of bidders in wildcat tracts could also explain the relative dearth of winning bidders with negative payoffs in these auctions. It must be noted, however, that our data is a preliminary first step, and additional work must be done before drawing strong conclusions about the applicability of our results to the field.

The primary contribution of this paper is to demonstrate that the behavior of bidders who only observe public information differs dramatically from those who additionally have access to private information. This paper is a first step in a much needed analysis of bidding behavior with only public information.

\section{A Derivations}

\section{A.1 Preliminaries}

The common value of the available good, $x$, is a realization of a random variable $X$ with a uniform distribution with support $[\underline{x}, \bar{x}]$. The realization of this value, $x$, is not observed by the two bidders before placing their bids. However, the distribution from which it is drawn is common knowledge.

In an SPRIV auction, bidder $i \in\{1,2\}$ observes an estimate of the realized value of the good. Each estimate is the realization of $X$ plus an error term $X_{i}$. This error term is $U(-\delta, \delta)$, and is independent of $X$ and $X_{-i}$. That is, each estimate is a realization of $Z_{i}=X+X_{i}$. We denote the distribution function of $Z_{i}$ as $F_{Z_{i}}$. Notice that $Z_{i}$ is independent

of $Z_{-i}$, conditional on the realization of $X$. Throughout, we use $f_{A}$ to denote the density function of the random variable $A$. A joint density function will be denoted as $f(\mathbf{x})$ where the vector $\mathbf{x}$ indicates the random variables for which $f(\mathbf{x})$ pertains.

\section{A.2 Symmetric and private information structure (SPRIV)}

The derivations to find the symmetric Nash equilibrium bid function can be found in Kagel and Levin (2002) and Kagel and Richard (2001). Assume that bidder $j \neq i$ bids according to the symmetric Nash equilibrium bid function, $\gamma\left(z_{j}\right)$. Consider bidder $i$ who observes a signal $z_{i}$ but bids as though she observed $y$. If $a\left(z_{i}\right)=\max \left(\underline{x}, z_{i}-\delta\right)$ and $b\left(z_{i}\right)=\min \left(\bar{x}, z_{i}+\delta\right)$, 
then the expected payoff of such a bidder is as follows:

$$
\begin{aligned}
\Pi\left(z_{i}, y\right) & =\int_{a\left(z_{i}\right)}^{b\left(z_{i}\right)}(x-\gamma(y)) F_{Z_{i} \mid X}(y \mid x) f_{X \mid Z_{i}}\left(x \mid z_{i}\right) d x \\
& =\int_{a\left(z_{i}\right)}^{b\left(z_{i}\right)}(x-\gamma(y))\left(\frac{y-x+\delta}{2 \delta}\right)\left(\frac{1}{b\left(z_{i}\right)-a\left(z_{i}\right)}\right) d x
\end{aligned}
$$

The revelation principle tells us that:

$$
\left.\frac{d \Pi\left(z_{i}, y\right)}{d y}\right|_{y=z_{i}}=0 .
$$

Using the initial condition $\gamma(\underline{x}-\delta)=\underline{x}$ and assuming continuity of the equilibrium bid function yields the solution:

$$
\gamma\left(z_{i}\right)=\left\{\begin{array}{ccc}
\underline{x}+\frac{1}{3}\left(z_{i}-\underline{x}+\delta\right) & \text { if } & z_{i} \in[\underline{x}-\delta, \underline{x}+\delta) \\
z_{i}-\delta+\frac{2 \delta}{3} \exp \left[\frac{1}{\delta}\left(\underline{x}+\delta-z_{i}\right)\right] & \text { if } \quad z_{i} \in[\underline{x}+\delta, \bar{x}-\delta) \\
\frac{2 \bar{x}^{3}+z_{i}^{3}+3 \delta z_{i}^{2}-9 \delta^{2} z_{i}+12 \delta \bar{x}\left(z_{i}+3 \delta\right)-3 \bar{x}^{2}\left(z_{i}+5 \delta\right)+\delta^{3}\left(8 \exp \left[\frac{2 \delta+\underline{x}-\bar{x}}{\delta}\right]-35\right)}{3\left(z_{i}-\bar{x}+3 \delta\right)^{2}} & \text { if } & z_{i} \in[\bar{x}-\delta, \bar{x}+\delta] .
\end{array}\right.
$$

The expected payoff of bidder $i$ when she observes a private signal $z_{i}$ is

$$
\begin{aligned}
\Pi_{i}^{S P R I V}\left(z_{i}\right) & =\int_{a\left(z_{i}\right)}^{b\left(z_{i}\right)}\left(x-\gamma\left(z_{i}\right)\right) F_{Z_{i} \mid X}\left(z_{i} \mid x\right) f_{X \mid Z_{i}}\left(x \mid z_{i}\right) d x \\
& =\int_{a\left(z_{i}\right)}^{b\left(z_{i}\right)}\left(x-\gamma\left(z_{i}\right)\right)\left(\frac{z_{i}-x+\delta}{2 \delta}\right)\left(\frac{1}{b\left(z_{i}\right)-a\left(z_{i}\right)}\right) d x
\end{aligned}
$$

This simplifies to

$$
\Pi_{i}^{S P R I V}\left(z_{i}\right)= \begin{cases}0 & \text { if } \quad z_{i} \in[\underline{x}-\delta, \underline{x}+\delta) \\ \frac{\delta}{3}\left(1-\exp \left(\frac{\underline{x}-z_{i}+\delta}{\delta}\right)\right) & \text { if } \quad z_{i} \in[\underline{x}+\delta, \bar{x}-\delta) \\ \frac{\bar{x}^{2}+z_{i}^{2}+4 z_{i} \delta+\delta^{2}\left(5-2 \exp \left(2-\frac{(\bar{x}-\underline{x})}{\delta}\right)\right)-2 \bar{x}\left(z_{i}+2 \delta\right)}{3\left(z_{i}-\bar{x}+3 \delta\right)} & \text { if } \quad z_{i} \in[\bar{x}-\delta, \bar{x}+\delta] .\end{cases}
$$

Bidder $i$ 's ex-ante expected payoff is obtained by integrating over $z_{i}$. This yields

$$
\begin{aligned}
E\left(\Pi_{i}^{S P R I V}\right) & =\int_{\underline{x}-\delta}^{\bar{x}+\delta} \Pi_{i}^{S P R I V}\left(z_{i}\right) f_{Z_{i}}\left(z_{i}\right) d z_{i} \\
& =\frac{\delta(3 \underline{x}-3 \bar{x}+\delta(13-12 \ln (2)))+3 \delta^{2} \exp \left(\frac{2 \delta+\underline{x}-\bar{x}}{\delta}\right)(\ln (16)-3)}{9(\underline{x}-\bar{x})} .
\end{aligned}
$$

For the parameter's employed in our design, $E\left(\Pi_{i}^{S P R I V}\right)=2.50019$. Since the ex-ante 
expected revenue in an auction is the expected value of the good, minus the ex-ante expected payoffs of the bidders, the ex-ante expected revenue of a SPRIV auction, $E\left(R^{S P R I V}\right)$, is

$$
\begin{aligned}
E\left(R^{S P R I V}\right) & =\left(\frac{\bar{x}+\underline{x}}{2}\right)- \\
& \frac{2 \delta(3 \underline{x}-3 \bar{x}+\delta(13-12 \ln (2)))+6 \delta^{2} \exp \left(\frac{2 \delta+\underline{x}-\bar{x}}{\delta}\right)(\ln (16)-3)}{9(\underline{x}-\bar{x})} .
\end{aligned}
$$

For the parameters in our design, this is $E\left(R^{S P R I V}\right)=119.99962$.

We also derive the break-even bidding strategy. If all bidders bid according to a monotonically increasing bid function, the bidder with the highest signal wins the auction. Therefore, if bidders are bidding according to a monotonically increasing bid function, bidders guarantee themselves negative profits if they bid more that the expected value of the good conditional on having the highest signal. Thus, the break-even bidding strategy for a SPRIV auction is given by:

$$
E\left(X \mid Z_{i}=z_{i}>Z_{j}\right)=\left\{\begin{array}{ccc}
\frac{1}{3}\left(z_{i}+2 \underline{x}+\delta\right) & \text { if } & z_{i} \in[\underline{x}-\delta, \underline{x}+\delta) \\
z_{i}-\frac{\delta}{3} & \text { if } & z_{i} \in[\underline{x}+\delta, \bar{x}-\delta) \\
\frac{\left(z_{i}+5 \delta\right)\left(z_{i}-\delta\right)+\bar{x}\left(z_{i}+5 \delta\right)-2 \bar{x}^{2}}{3\left(z_{i}-\bar{x}+3 \delta\right)} & \text { if } & z_{i} \in[\bar{x}-\delta, \bar{x}+\delta]
\end{array}\right.
$$

\section{A.3 Asymmetric information structure (ASYM)}

Engelbrecht-Wiggans et al. (1983) provide the unique equilibrium of this game. We denote the informed bidder as bidder $I$. In this equilibrium, when the informed bidder observes $z_{I}$ she bids according to the function

$$
\begin{aligned}
\beta\left(z_{I}\right) & =E\left(E\left(X \mid Z_{I}\right) \mid Z_{I} \leq z_{I}\right) \\
& =\frac{1}{F_{Z_{I}}\left(z_{I}\right)} \int_{\underline{x}-\delta}^{z_{I}} E\left(X \mid Z_{I}=s\right) f_{Z_{I}}(s) d s .
\end{aligned}
$$

For the distribution functions used in our experimental design the equilibrium bid function for the informed bidder in an ASYM auction is

$$
\beta\left(z_{I}\right)=\left\{\begin{array}{lll}
\frac{2 \underline{x}+z_{I}+\delta}{3} & \text { if } & z_{I} \in[\underline{x}-\delta, \underline{x}+\delta) \\
\frac{z_{I}+\underline{x}}{2}+\frac{\delta^{2}}{6\left(z_{I}-\underline{x}\right)} & \text { if } & z_{I} \in[\underline{x}+\delta, \bar{x}-\delta) \\
\frac{2 \bar{x}^{3}+\left(z_{I}-\delta\right)^{3}+6 \underline{x}^{2} \delta-3 \bar{x}^{2}\left(z_{I}+\delta\right)}{3\left(\bar{x}^{2}+\left(z_{I}-\delta\right)^{2}+4 \underline{x} \delta-2 \bar{x}\left(z_{I}+\delta\right)\right)} & \text { if } & z_{I} \in[\bar{x}-\delta, \bar{x}+\delta] .
\end{array}\right.
$$

In equilibrium, the uninformed bidder will mix on the interval $[\underline{x}, E(X)]$ according to 
the following distribution function:

$$
\begin{aligned}
Q(b) & =\operatorname{Prob}\left[\beta\left(Z_{I}\right) \leq b\right] \\
& =F_{Z_{I}}\left(\beta^{-1}(b)\right) .
\end{aligned}
$$

So, the uninformed bidder will mix accordingly using this distribution function:

$$
Q(b)=\left\{\begin{array}{ccc}
\frac{\left(\beta^{-1}(b)-\underline{x}+\delta\right)^{2}}{4 \delta(\bar{x}-\underline{x})} & \text { if } \quad b \in[\beta(\underline{x}-\delta), \beta(\underline{x}+\delta)) \\
\frac{\beta^{-1}(b)-\underline{x}}{(\bar{x}-\underline{x})} & \text { if } \quad b \in[\beta(\underline{x}+\delta), \beta(\bar{x}-\delta)) \\
\frac{4 \delta(\bar{x}-\underline{x}-\delta)+\left(\bar{x}+3 \delta-\beta^{-1}(b)\right)\left(\beta^{-1}(b)-\bar{x}+\delta\right)}{4 \delta(\bar{x}-\underline{x})} & \text { if } b \in[\beta(\bar{x}-\delta), \beta(\bar{x}+\delta)] .
\end{array}\right.
$$

Engelbrecht-Wiggans et al. (1983) show that, in equilibrium, the uninformed bidder obtains an expected payoff of zero for any bid in the support of $Q(b)$. Let $q\left(z_{I}\right):=E\left(X \mid z_{I}\right)$. Since $q\left(z_{I}\right)$ is monotonically increasing in $z_{I}$, the distribution function of this random variable is just $F_{Z_{I}}\left(q^{-1}(\cdot)\right)$, where $q^{-1}(\cdot)$ is the inverse of $q(\cdot)$. Engelbrecht-Wiggans et al. (1983) also demonstrate that when the informed bidder observes $z_{I}$ her expected payoff is

$$
\Pi_{I}^{A S Y M}\left(z_{I}\right)=\int_{\underline{x}}^{q\left(z_{I}\right)} F_{Z_{I}}\left(q^{-1}(s)\right) d s .
$$

That is, the expected payoff of an informed bidder is

$$
\Pi_{I}^{A S Y M}\left(z_{I}\right)=\left\{\begin{array}{ccc}
\frac{\left(z_{I}-\underline{x}+\delta\right)^{3}}{24 \delta(\bar{x}-\underline{x})} & \text { if } & z_{I} \in[\underline{x}-\delta, \underline{x}+\delta) \\
\frac{3\left(\underline{x}-z_{I}\right)^{2}-\delta^{2}}{6(\bar{x}-\underline{x})} & \text { if } & z_{I} \in[\underline{x}+\delta, \bar{x}-\delta) \\
\frac{\left(\bar{x}-z_{I}+\delta\right)^{3}}{24 \delta(\bar{x}-\underline{x})}+\frac{\left(\bar{x}+z_{I}-\delta\right)}{2}-\frac{(\bar{x}+\underline{x})}{2} & \text { if } & z_{I} \in[\bar{x}-\delta, \bar{x}+\delta]
\end{array}\right.
$$

The ex-ante expected payoff of the informed bidder can be found by integrating over $z_{I}$. This yields

$$
\begin{aligned}
E\left(\Pi_{I}^{A S Y M}\right) & =\int_{\underline{x}-\delta}^{\bar{x}+\delta} \Pi_{I}^{A S Y M}\left(z_{I}\right) f_{Z_{I}}\left(z_{I}\right) d z_{I} \\
& =\frac{5(\bar{x}-\underline{x})^{3}-10 \delta^{2}(\bar{x}-\underline{x})+8 \delta^{3}}{30(\bar{x}-\underline{x})^{2}} .
\end{aligned}
$$

For the parameters employed in our design, $E\left(\Pi_{I}^{A S Y M}\right)=33.2301$. The ex-ante expected revenue for the seller is found by subtracting the ex-ante expected payoff of the informed 
bidder from the expected value of $X$. This yields

$$
E\left(R^{A S Y M}\right)=\frac{\bar{x}+\underline{x}}{2}-\left(\frac{5(\bar{x}-\underline{x})^{3}-10 \delta^{2}(\bar{x}-\underline{x})+8 \delta^{3}}{30(\bar{x}-\underline{x})^{2}}\right)
$$

For the parameter values used in our design $E\left(R^{A S Y M}\right)=91.7699$.

Since the uninformed bidder has an expected payoff of zero for any bid $b \in[\underline{x}, E(X)]$, $E(X)$ is the break-even bidding threshold for uninformed ASYM bidders. Bidding above $E(X)$ ensures negative expected profit upon winning, while bidding below $E(X)$ yields an expected payoff of zero conditional on winning the auction.

The expected value of the good conditional on $z_{I}$ is the same as the expected value of the good conditional on $z_{I}$ and having won the auction. Winning the auction does not provide the informed bidder additional information regarding $x$. Therefore, the break-even bidding threshold for an informed ASYM bidder is to bid:

$$
E\left(X \mid Z_{I}=z_{I}\right)=\left\{\begin{array}{ccc}
\frac{z_{I}+\delta+\underline{x}}{2} & \text { if } & z_{I} \in[\underline{x}-\delta, \underline{x}+\delta) \\
z_{I} & \text { if } & z_{I} \in[\underline{x}+\delta, \bar{x}-\delta) \\
\frac{z_{I}-\delta+\bar{x}}{2} & \text { if } & z_{I} \in[\bar{x}-\delta, \bar{x}+\delta] .
\end{array}\right.
$$

\section{B Instructions for ASYM sessions}

\section{Introduction}

Welcome. This experiment is about decision making in markets. The following instructions describe the markets you will be in and the rules that you will face. The decisions you make during this experiment will determine how much money you earn. If you make good decisions, you can earn a substantial amount of money. You will be paid in cash privately at the end of our experiment.

It is important that you remain silent and do not look at other people's work. If you have any questions, or need assistance of any kind, please raise your hand and an experimenter will come to you. If you talk, laugh, exclaim out loud, etc., you will be asked to leave and you will not be paid. We expect and appreciate your cooperation.

We will go over these instructions with you. After we have read the instructions, there will be time to ask clarifying questions. When we are done going through the instructions, each of you will have to answer a few brief questions to ensure everyone understands.

\section{Overview}

Our experiment will consist of 30 rounds. In each of these rounds, you will be randomly paired with another participant in today's experiment. Both of you will be buyers in a 
market. In each market, there will be a single unit of an indivisible good for sale. As a buyer, your task is to submit a bid for the purchase of the good. You will receive earnings based on the outcome of the market. This process will be repeated until all 30 rounds have been completed.

\section{Determination of Your Earnings}

Each participant will receive a show-up fee of $\$ 5$. In addition, each participant in this experiment will start with a balance of $\$ 3,200$ "experimental dollars" (EDs). EDs will be traded in for cash at the end of the experiment at a rate of $\$ 160 E D=\$ 1$. Your starting balance can increase or decrease depending on your payoffs in each round. That is, if you have a negative payoff in a round, this loss will be deducted from your balance. If you earn a positive payoff, this is added to your balance. You are permitted to bid more than your remaining balance. However, if after a round is completed your balance is less than or equal to zero, you will not be able to participate in any future rounds.

In each round, you and the other buyer in the market will submit a bid. The higher bid will have to be paid, and the buyer with the higher bid will receive the good. The buyer who submits the lower bid does not get the good, but does not pay his/her bid. That is, for each market, the buyer who submits the higher bid will receive:

(Value of the good) $-($ Own bid $)$

The person who submits the lower bid will receive:

0

If both buyers bid the same amount, then the winner is determined randomly, with both buyers having equal probability of receiving the good. You can think of this as a flip of a fair coin, which determines the winner in the event of a tie. Only the bidder who receives the good must pay his/her bid.

Notice that the buyer who submits the highest bid can end up with a negative payoff, if he/she bids more than the good is worth. No buyer is permitted to submit a bid that is lower than zero.

In each round, the value of the good, which we will denote as $v^{*}$, will not be known to the buyers. The value of this good will be between $\$ 25 E D$ and $\$ 225 E D$. Any value between $\$ 25 E D$ and $\$ 225 E D$ is equally likely to be chosen as $v^{*}$. The value of the good in any given round is independent of the value in any other round. That is, the value of the good in one round will not have any effect on the value of the good in a different round.

\section{Private Information}




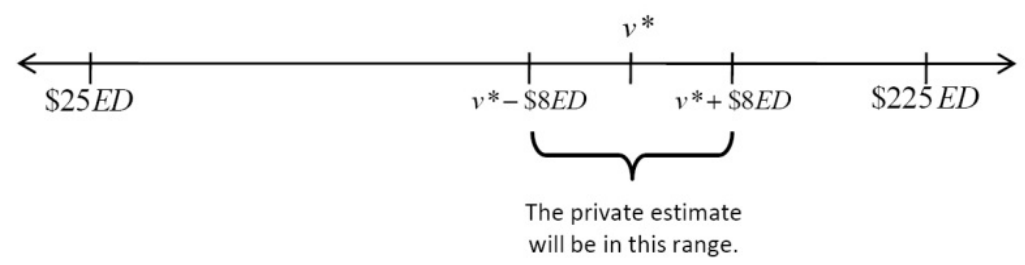

In each market, one of the two buyers will be randomly chosen to receive some private information about the value of the good (you can think of this as flipping a coin to determine which of the buyers will receive this information, where the probability of the coin landing on each side is 50\%). The person who receives the private information will be given an estimate of the value of the good. The estimate will be a randomly chosen number that is within $\$ 8 E D$ above or below the real value of $v^{*}$ (see the illustration below). Any number between $v^{*}-\$ 8 E D$, and $v^{*}+\$ 8 E D$ is equally likely to be chosen as the estimate. For example, if you receive an estimate of $\$ 125 E D$, then you know that $v^{*}$ is between $\$ 117 E D$ and $\$ 133 E D$, inclusive. It is possible for the estimate to be a value below $\$ 25 E D$ or above $\$ 225 E D$, but the real value of $v^{*}$ will always be between $\$ 25 E D$ and $\$ 225 E D$.

\section{Rounds}

As mentioned before, there will be 30 rounds in this experiment. In each round there will be several markets going on simultaneously, with two buyers in each market. After each round you will be randomly paired with another participant in today's experiment. This random assignment is done every round so that two buyers will probably not be in the same market together for two consecutive rounds. Further, this pairing is anonymous. That is, if you are a buyer in a given market, you do not know which of the other participants in the experiment is the other buyer in that market. Remember that these different markets and rounds are independent from all others, and from one another. The bids and the value of the good and the estimate in one market or round do not have any effect on other markets or rounds. Markets and rounds operate independently.

\section{Summary}

1. Each participant has a starting balance of $\$ 3,200 E D$.

2. In every round, each participant will be a buyer in one market. Two participants are randomly assigned to a market in each round.

3. The value of the good, $v^{*}$, is unknown. It is known that it is somewhere between $\$ 25 E D$ and $\$ 225 E D$. Every value between $\$ 25 E D$ and $\$ 225 E D$ is equally likely to be $v^{*}$. 
4. One buyer in a market is randomly chosen to receive an estimate of $v^{*}$. A buyer's estimate is not observed by the other buyer in the market. These estimates are randomly and independently drawn from the interval between $v^{*}-\$ 8 E D$ and $v^{*}+\$ 8 E D$, inclusive. Any number from this interval is equally likely to be chosen as the estimate.

5. In each market the high bidder gets $v^{*}-($ Own bid), and the low bidder gets 0 . This payoff is added to the balance of each bidder (a bidder's balance will go down if the value is negative, up if this value is positive, and remain unchanged if this value is zero).

6. Every participant will receive the show-up fee of $\$ 5$. Additionally, each participant will receive his/her balance at the end of all 30 rounds, based on the $\$ 3,200 E D$ beginning balance and earnings in each market.

7. If a participant's balance should become negative at any point during this experiment, he/she will not be permitted to participate in future rounds.

If you have any questions, raise your hand and one of us will come help you. Please do not ask any questions out loud.

\section{Questions}

Before we begin the experiment, we would like you to answer a few questions that are meant to review the rules of today's experiment. Please raise your hand once you are done, and an experimenter will attend to you.

1. How many buyers are in each market?

2. Who pays their bid in each market, the high bidder, the low bidder, or both?

3. Each estimate must be within what range of $v^{*}$ ?

4. Are you allowed to bid more than your current balance?

5. For each market, how many buyers get to see an estimate of $v^{*}$ ?

6. If the highest bid in a market is $\$ 152.10 E D$, and the value of the good is revealed to be $\$ 200.90 E D$, what is the winner's payoff for that market?

7. What would the earnings from question six have been if the value of the good had been $\$ 25.90 E D ?$

8. If Buyer 1 bids $\$ 150.00 E D$, and Buyer 2 bids $\$ 200.00 E D$, and the value of the good is revealed to be $\$ 220.75 E D$, what are the payoffs for Buyer 1 and Buyer 2 ? 


\section{SPUB equilibrium with risk and loss averse bidders}

Consider an SPUB auction with $n \geq 2$ bidders. Assume that all bidders have the same utility function $u(x)$ which is strictly increasing in $x$, strictly concave for $x \geq 0$ and strictly convex for $x<0$. Assume that $u(0)=0$.

If a symmetric equilibrium exists in pure strategies, it must be the case that the equilibrium expected utility of winning the auction is 0 , and the expected utility of increasing the bid above the equilibrium must be negative. If this were not the case, then any bidder could increase her bid by an infinitesimal amount, while increasing her payoff by a non-infinitesimal amount. That is, any bidder could break the resulting tie with an arbitrarily small increase in her bid, and win the good with certainty (resulting in positive expected utility). In a symmetric equilibrium no bidder would have an incentive to bid less, because their payoff would remain 0 .

To establish the existence of such an equilibrium, it is sufficient to show that

$$
\int_{25}^{225} u(v-b) f(v) d v=0
$$

for some $b \geq 0$, and that this expression is strictly monotonically decreasing in $b$. Note that this expression is continuous, and that the partial derivative with respect to $b$ is negative. Since $\int_{25}^{225} u(v-0) f(v) d v>0$ and $\int_{25}^{225} u(v-225) f(v) d v<0$, then the intermediate value theorem establishes the result. Note that this also establishes the uniqueness of the symmetric equilibrium. ${ }^{55}$ Notice that equilibrium does not depend on the number of bidders.

Suppose that the utility function of each of the bidders is given by

$$
u(x)= \begin{cases}x^{\alpha} & x \geq 0 \\ -\lambda x^{\beta} & x<0 .\end{cases}
$$

Note that when $\alpha=\beta$ and $\lambda=1$, the bid which satisfies $\int_{25}^{225}(v-b)^{\alpha}\left(\frac{1}{200}\right) d v=0$ is $b=125$ which is thus the unique symmetric equilibrium.

Now consider the case where $\alpha=0.730$ and $\beta=0.733$ as well as the loss aversion parameter $\lambda=1.381$. These parameter values are taken from the conditional model of Harrison and Rutström (2009), without individual covariates. For simplicity, we assume that there is no nonlinear probability weighting. The unique symmetric equilibrium is then given by $b=115.6972$.

\footnotetext{
${ }^{55}$ When $n>2$ there are also asymmetric eqilibria in which at least two of the bidders choose to bid at the symmetric equilibrium bid, and each of the remaining bidders bid anything less than this bid (or mix on some interval weakly less than this bid). For simplicity, we restrict our attention to symmetric equilibria.
} 
Now consider the case in which all bidders employ the same nonlinear probability weighting function. If we assume the functional form for this nonlinear probability weighing function is as suggested in Tversky and Kahneman (1992) then the weight (which gives the transformed distribution function) is given by

$$
w(v)=\frac{F(v)^{\gamma}}{\left(F(v)^{\gamma}+(1-F(v))^{\gamma}\right)^{\frac{1}{\gamma}}} .
$$

Harrison and Rutström (2009) estimate that $\gamma=0.942$. The unique symmetric equilibrium using these parameters is given by $b=115.5073 .{ }^{56}$

\section{SPUB auctions and level-k reasoning}

Following Crawford and Iriberri (2007), we assume a logit error structure. Denoting bidder $i$ 's level $k$ belief about her expected profit when there are $n$ bidders in the auction and she bids $b_{i t}$ in period $t$ as $\prod_{i t}^{n k}\left(b_{i t}\right)$, the probability of observing bid $b_{i t}$ when the bidder is level $k$ (assuming bidder $i$ is not level zero) is assumed to be

$$
\operatorname{Pr}_{n k}\left(b_{i t}, \lambda_{n k}\right)=\frac{\exp \left(\lambda_{n k} \prod_{i t}^{n k}\left(b_{i t}\right)\right)}{\sum_{x=0}^{225} \exp \left(\lambda_{n k} \prod_{i t}^{n k}(x)\right)}
$$

$\lambda_{n k}$ is the logit precision parameter for bidders of level $k$ when there are $n$ bidders in the auction, which determines how likely a bidder is to choose a bid that is not a best response. If $\lambda_{n k}=0$, then the bidder is uniformly randomizing over the set of possible bids. As $\lambda_{n k} \rightarrow \infty$ the probability that the bidder best responds approaches one. We assume that errors in choosing bids are independent across periods and individuals. Additionally, we assume that a bidder's level does not change over time. For subject $i$ who is level $k$ we observe a sequence of bids $b_{i}=\left(b_{i 1}, b_{i 2}, \ldots, b_{i 30}\right)$. If, when there are $n$ bidders in the auction, bidder $i$ is level $k$, then the likelihood of observing $b_{i}$ is given by

$$
L_{n k}\left(b_{i}\right)=\prod_{t=1}^{30} P r_{n k}\left(b_{i t}, \lambda_{n k}\right)
$$

\footnotetext{
${ }^{56}$ We also calculate the equilibrium with various other parameter estimates for $\alpha, \beta, \lambda$ and $\gamma$ from the literature. In no case do these estimates rationalize our SPUB data.
} 
Again following Crawford and Iriberri (2007), we assume that bidders are either level zero, level one or level two. ${ }^{57}$ Denote the proportion of level $k$ bidders when there are $n$ bidders in the auction as $\pi_{n k}$. Then, the likelihood of observing $b_{i}$, without conditioning on the level of bidder $i$, is given by

$$
\pi_{n 0} \prod_{t=1}^{30}\left(\frac{1}{20001}\right)+\pi_{n 1} \prod_{t=1}^{30} \operatorname{Pr}_{n 1}\left(b_{i t}, \lambda_{n 1}\right)+\pi_{n 2} \prod_{t=1}^{30} \operatorname{Pr}_{n 2}\left(b_{i t}, \lambda_{n 2}\right)
$$

When $n=2$ there are a total of 80 subjects. When $n=4$ there are a total of 60 subjects, and when $n=6$ there are a total of 90 subjects. Thus, the log-likelihood of observing our sample is given by

$$
\begin{aligned}
L L= & \sum_{i=1}^{80} \ln \left(\pi_{20} \prod_{t=1}^{30}\left(\frac{1}{20001}\right)+\pi_{21} \prod_{t=1}^{30} \operatorname{Pr}_{21}\left(b_{i t}, \lambda_{21}\right)+\pi_{22} \prod_{t=1}^{30} \operatorname{Pr}_{22}\left(b_{i t}, \lambda_{22}\right)\right) \\
& +\sum_{i=1}^{60} \ln \left(\pi_{40} \prod_{t=1}^{30}\left(\frac{1}{20001}\right)+\pi_{41} \prod_{t=1}^{30} \operatorname{Pr}_{41}\left(b_{i t}, \lambda_{41}\right)+\pi_{42} \prod_{t=1}^{30} \operatorname{Pr}_{42}\left(b_{i t}, \lambda_{42}\right)\right) \\
& +\sum_{i=1}^{90} \ln \left(\pi_{60} \prod_{t=1}^{30}\left(\frac{1}{20001}\right)+\pi_{61} \prod_{t=1}^{30} \operatorname{Pr}_{61}\left(b_{i t}, \lambda_{61}\right)+\pi_{62} \prod_{t=1}^{30} \operatorname{Pr}_{62}\left(b_{i t}, \lambda_{62}\right)\right) .
\end{aligned}
$$

We estimate two models. In one of these $\pi_{n 0}$ is assumed to be 0 for $n \in\{2,4,6\}$, while in the other there is no such restriction. A model with this restriction is of interest for two reasons. First, it is unlikely that there are any subjects whose behavior is truly random. Second, random bidding behavior is already implicitly included in the model via the precision parameters $\lambda_{n k}$. The estimates for both of these models are reported in Table 8.

\section{References}

Olivier Armantier. Does observation influence learning? Games and Economic Behavior, 46 (2):221-239, 2004.

Max H. Bazerman and William F. Samuelson. I won the auction but don't want the prize. Journal of Conflict Resolution, 27(4):618-634, 1983.

Anabela Botelho, Glenn W. Harrison, Lígia M. Costa Pinto, and Elisabet E. Rutström. Testing static game theory with dynamic experiments: A case study of public goods. Games and Economic behavior, 67(1):253-265, 2009.

\footnotetext{
${ }^{57}$ The best response of a level three bidder is simply 0.01 above that of a level two bidder, the best response of a level four bidder is 0.01 above that of a level three bidder, and so on.
} 
Colin M. Campbell and Dan Levin. Can the seller benefit from an insider in common-value auctions? Journal of Economic Theory, 91(1):106-120, 2000.

Marco Casari, John C. Ham, and John H. Kagel. Selection bias, demographic effects, and ability effects in common value auction experiments. American Economic Review, 97(4): 1278-1304, 2007.

James Cox, Sam Dinkin, and James Swarthout. Endogenous entry and exit in common value auctions. Experimental Economics, 4(2):163-181, 2001.

Vincent P. Crawford and Nagore Iriberri. Level-k auctions: Can boundedly rational strategic thinking explain the winner's curse and overbidding in private-value auctions? Econometrica, 75(6):1721-1770, 2007.

Dakshina De Silva, Thomas Jeitschko, and Georgia Kosmopoulou. Entry and bidding in common and private value auctions with an unknown number of rivals. Review of Industrial Organization, 35(1):73-93, 2009.

Richard Engelbrecht-Wiggans, Paul R. Milgrom, and Robert J. Weber. Competitive bidding and proprietary information. Journal of Mathematical Economics, 11(2):161-169, 1983.

Erik Eyster and Matthew Rabin. Cursed equilibrium. Econometrica, 73(5):1623-1672, 2005.

Nick Feltovich. Nonparametric tests of differences in medians: Comparison of the wilcoxonmann-whitney and robust rank-order tests. Experimental Economics, 6(3):273-297, 2003.

Urs Fischbacher. z-tree: Zurich toolbox for ready-made economic experiments. Experimental Economics, 10(2):171-178, 2007.

Glenn Harrison and John List. Naturally occurring markets and exogenous laboratory experiments: A case study of the winner's curse. Economic Journal, 118(528):822-843, 2008.

Glenn W. Harrison and Elisabet Rutström. Expected utility theory and prospect theory: one wedding and a decent funeral. Experimental Economics, 12(2):133-158, 2009.

Kenneth Hendricks and Robert H. Porter. An empirical study of an auction with asymmetric information. American Economic Review, pages 865-883, 1988.

Kenneth Hendricks, Robert H. Porter, and Bryan Boudreau. Information, returns, and bidding behavior in ocs auctions: 1954-1969. Journal of Industrial Economics, pages 517-542, 1987. 
Kenneth Hendricks, Robert H. Porter, and Richard H. Spady. Random reservation prices and bidding behavior in ocs drainage auctions. Journal of Law and Economics, pages S83-S106, 1989.

Kenneth Hendricks, Robert H. Porter, and Guofu Tan. Optimal selling strategies for oil and gas leases with an informed buyer. The American Economic Review, pages 234-239, 1993.

Kenneth Hendricks, Robert H. Porter, and Charles A. Wilson. Auctions for oil and gas leases with an informed bidder and a random reservation price. Econometrica, pages 1415-1444, 1994.

Kenneth Hendricks, Joris Pinkse, and Robert H. Porter. Empirical implications of equilibrium bidding in first-price, symmetric, common value auctions. Review of Economic Studies, 70(1):115-145, 2003.

John H. Kagel and Dan Levin. The winner's curse and public information in common value auctions. American Economic Review, 76(5):894-920, 1986.

John H. Kagel and Dan Levin. Common value auctions with insider information. Econometrica, 67(5):1219-1238, 1999.

John H. Kagel and Dan Levin. Common value auctions and the winner's curse. Princeton University Press, Princeton, N.J., 2002.

John H. Kagel and Jean-Francois Richard. Super-experienced bidders in first-price commonvalue auctions: Rules of thumb, nash equilibrium bidding, and the winner's curse. Review of Economics and Statistics, 83(3):408-419, 2001.

Paul R. Milgrom and Robert J. Weber. A theory of auctions and competitive bidding. Econometrica, 50(5):1089-1122, 1982.

Amos Tversky and Daniel Kahneman. Advances in prospect theory: cumulative representation of uncertainty. Journal of Risk and Uncertainty, 5(4):297-323, 1992. 
Table 1: Bids relative to the Nash equilibrium

\begin{tabular}{cccc}
\hline & Observed bids & Nash bids & Percent observed bids are over Nash \\
\hline ASYM-Informed & 77.94 & 69.54 & $10 \%$ \\
& $(41.84)$ & $(27.65)$ & $(0.35)$ \\
ASYM-Uninformed $^{a}$ & 57.81 & 75.23 & $-23 \%$ \\
& $(30.99)$ & $(28.64)$ & $(0.42)$ \\
SPUB & 72.57 & 125 & $-42 \%$ \\
& $(23.62)$ & $(0.00)$ & $(0.11)$ \\
SPRIV & 108.34 & 105.93 & $(0.11)$ \\
\hline
\end{tabular}

Note: Table contains means with standard deviations in parentheses. The unit of observation for this table is the individual bid. The number of observations is 1500 for SPUB and SPRIV bids. There are only 750 observations of both informed and uninformed ASYM bids. Nash bids are calculated using the realized signals when applicable.

${ }^{a}$ Uninformed ASYM bidders are predicted to play a mixed strategy. We report the expected value and standard deviation of this strategy in the second column, and compare observed bids to the expected value of this strategy in the last column. 
Table 2: Frequency of bids above break-even threshold

\begin{tabular}{ccc}
\hline & All bidders & Winning bidders \\
\hline ASYM-Informed & $6 \%$ & $6.9 \%$ \\
& $(45 / 750)$ & $(34 / 491)$ \\
ASYM-Uninformed & $3.3 \%$ & $9.7 \%$ \\
& $(28 / 750)$ & $(25 / 259)$ \\
SPUB & $1.6 \%$ & $3.2 \%$ \\
& $(24 / 1500)$ & $(24 / 750)$ \\
SPRIV & $30.9 \%$ & $45.3 \%$ \\
& $(464 / 1500)$ & $(340 / 750)$ \\
\hline
\end{tabular}

Note: Table contains the percentage of bids in excess of the break-even bidding threshold. The numbers in parentheses reflect the observed number of such bids. The unit of observation for this table is the individual bid. The number of observations is 1500 for SPUB and SPRIV bids. There are only 750 observations for both informed and uninformed ASYM bids. When attention is restricted to winning bidders, there are 491 winning bids by informed ASYM bidders, and 259 winning bids by uninformed ASYM bidders. 
Table 3: Tobit estimates of bid functions

\begin{tabular}{|c|c|c|c|c|c|}
\hline & $\begin{array}{c}\text { Informed ASYM } \\
\text { bidders }\end{array}$ & $\begin{array}{l}\text { Uninformed ASYM } \\
\text { bidders }\end{array}$ & $\begin{array}{l}\text { SPUB } \\
\text { bidders }\end{array}$ & $\begin{array}{l}\text { SPRIV } \\
\text { bidders }\end{array}$ & Joint \\
\hline$z_{i t}$ & $\begin{array}{c}0.568^{* * *} \\
(0.018)\end{array}$ & $\begin{array}{l}-0.022 \\
(0.021)\end{array}$ & $\begin{array}{l}-0.014 \\
(0.011)\end{array}$ & $\begin{array}{c}0.989^{* * *} \\
(0.005)\end{array}$ & $\begin{array}{l}-0.014 \\
(0.010)\end{array}$ \\
\hline $\ln (1+t)$ & $\begin{array}{c}-12.072^{* * *} \\
(1.420)\end{array}$ & $\begin{array}{c}-5.113^{* * *} \\
(1.627)\end{array}$ & $\begin{array}{c}4.400^{* * *} \\
(0.846)\end{array}$ & $\begin{array}{l}-0.084 \\
(0.356)\end{array}$ & $\begin{array}{c}4.400^{* * *} \\
(0.793)\end{array}$ \\
\hline$M_{i}$ & $\begin{array}{c}-5.260^{* * *} \\
(1.915)\end{array}$ & $\begin{array}{l}-3.317 \\
(2.384)\end{array}$ & $\begin{array}{l}-0.734 \\
(1.211)\end{array}$ & $\begin{array}{c}-2.137^{* * *} \\
(0.474)\end{array}$ & $\begin{array}{l}-0.734 \\
(1.135)\end{array}$ \\
\hline$m\left(z_{i t}\right)$ & $\begin{array}{l}-0.199 \\
(0.208)\end{array}$ & & & & \\
\hline$g\left(z_{i t}\right)$ & & & & $\begin{array}{c}0.093 \\
(0.089)\end{array}$ & \\
\hline$S P R I V_{i t}$ & & & & & $\begin{array}{l}-65.359^{* * *} \\
(3.543)\end{array}$ \\
\hline$A I N F_{i t}$ & & & & & $\begin{array}{l}-14.645^{* * *} \\
(4.368)\end{array}$ \\
\hline$A U N F_{i t}$ & & & & & $\begin{array}{l}12.477^{* * *} \\
(4.346)\end{array}$ \\
\hline$S P R I V_{i t} \cdot z_{i t}$ & & & & & $\begin{array}{c}1.000^{* * *} \\
(0.015)\end{array}$ \\
\hline$A I N F_{i t} \cdot z_{i t}$ & & & & & $\begin{array}{c}0.582^{* * *} \\
(0.018)\end{array}$ \\
\hline$A U N F_{i t} \cdot z_{i t}$ & & & & & $\begin{array}{l}-0.008 \\
(0.018)\end{array}$ \\
\hline$S P R I V_{i t} \cdot \ln (1+t)$ & & & & & $\begin{array}{l}-4.491^{* * *} \\
(1.127)\end{array}$ \\
\hline$A I N F_{i t} \cdot \ln (1+t)$ & & & & & $\begin{array}{l}-16.470^{* * *} \\
(1.375)\end{array}$ \\
\hline$A U N F_{i t} \cdot \ln (1+t)$ & & & & & $\begin{array}{l}-9.644^{* * *} \\
(1.376)\end{array}$ \\
\hline$S P R I V_{i t} \cdot M_{i}$ & & & & & $\begin{array}{l}-1.411 \\
(1.613)\end{array}$ \\
\hline$A I N F_{i t} \cdot M_{i}$ & & & & & $\begin{array}{c}-4.560^{* *} \\
(2.004)\end{array}$ \\
\hline$A U N F_{i t} \cdot M_{i}$ & & & & & $\begin{array}{l}-2.318 \\
(2.001)\end{array}$ \\
\hline$A I N F_{i t} \cdot m\left(z_{i t}\right)$ & & & & & $\begin{array}{l}-0.209 \\
(0.177)\end{array}$ \\
\hline$S P R I V_{i t} \cdot g\left(z_{i t}\right)$ & & & & & $\begin{array}{c}0.101 \\
(0.211)\end{array}$ \\
\hline Constant & $\begin{array}{c}48.496^{* * *} \\
(4.448)\end{array}$ & $\begin{array}{c}75.194^{* * *} \\
(5.160)\end{array}$ & $\begin{array}{c}63.100^{* * *} \\
(2.652)\end{array}$ & $\begin{array}{c}-2.254^{* *} \\
(1.105)\end{array}$ & $\begin{array}{c}63.100^{* * *} \\
(2.485)\end{array}$ \\
\hline
\end{tabular}

Note: The unit of observation for this table is the individual bid. Standard errors are given in parentheses. The number of observations is 1500 for SPUB and SPRIV bids. There are only 750 observations of both informed and uninformed ASYM bids. ${ }^{*} p<0.05,{ }^{* *} p<0.01,{ }^{* * *} p<0.001$ 
Table 4: Summary statistics for payoffs

\begin{tabular}{ccc}
\hline & Observed payoffs & Predicted payoffs \\
\hline ASYM-Informed & 28.37 & 27.29 \\
& $(37.39)$ & $(27.7)$ \\
ASYM-Uninformed & -1.81 & 0 \\
& $(23.63)$ & $(0)$ \\
SPUB & 15.74 & 0 \\
& $(45.71)$ & $(0)$ \\
SPRIV & 1.59 & 2.43 \\
& $(5.66)$ & $(0.69)$ \\
\hline
\end{tabular}

Note: Table contains means with standard deviations in parentheses. The unit of observation for this table is the individual bid. The number of observations is 1500 for SPUB and SPRIV bids. There are only 750 observations for both informed and uninformed ASYM bids. Predicted payoffs are calculated using the realizations of signals when applicable. 
Table 5: Summary statistics for revenue

\begin{tabular}{ccc}
\hline & Observed revenue & Predicted revenue \\
\hline ASYM & 88.96 & $88.80^{a}$ \\
& $(37.33)$ & $(13.85)$ \\
SPUB & 84.06 & 125 \\
& $(21.87)$ & $(0)$ \\
SPRIV & 112.36 & 107.92 \\
& $(55.94)$ & $(55.17)$ \\
\hline
\end{tabular}

Note: Table contains means with standard deviations in parentheses. The unit of observation for this table is the individual auction. The number of observations is 750 . Predicted revenue is calculated using the realizations of signals when applicable.

${ }^{a}$ Predicted revenue of an ASYM auction is $E\left(\max \left(\beta\left(z_{I}\right), b_{u}\right)\right)$, where $b_{u}$ is the bid of the uninformed bidder. 
Table 6: Summary statistics for bidding and the payoffs of winning bidders in SPUB auctions with two, four or six bidders.

\begin{tabular}{ccccc}
\hline & Observed bid & Predicted bid & $\begin{array}{c}\text { Observed payoff of } \\
\text { winning bidders }\end{array}$ & $\begin{array}{c}\text { Predicted payoff of } \\
\text { winning bidders }\end{array}$ \\
\hline Two bidders & 75.36 & 125 & 35.52 & 0 \\
& $(32.47)$ & $(0)$ & $(66.54)$ & $(0)$ \\
Four bidders & 91.33 & 125 & 7.12 & 0 \\
& $(31.88)$ & $(0)$ & $(64.42)$ & $(0)$ \\
Six bidders & 108.2 & 125 & -22.83 & $(0)$ \\
& $(39.06)$ & $(0)$ & $(63.25)$ & 0 \\
\hline
\end{tabular}

Note: Table contains means with standard deviations in parentheses. The unit of observation for this table is the individual bid. When all (only winning) bids are considered there are 2700 (450) observations for auctions with six bidders, 1800 (450) observations for auctions with four bidders, and 900 (450) observations for auctions with two bidders. The data presented is from the sessions run at Centro Vernon Smith de Economía Experimental. 
Table 7: Frequency of bids above the breakeven bidding threshold in SPUB auctions with two, four or six bidders.

\begin{tabular}{ccc}
\hline & All bidders & Winning bidders \\
\hline Two bidders & $5 \%$ & $10 \%$ \\
& $(45 / 900)$ & $(45 / 450)$ \\
Four bidders & $12 \%$ & $40 \%$ \\
& $(215 / 1800)$ & $(178 / 450)$ \\
Six bidders & $36 \%$ & $89 \%$ \\
& $(987 / 2700)$ & $(401 / 450)$ \\
\hline
\end{tabular}

Note: Table contains the percentage of bids in excess of the break-even bidding threshold. The numbers in parentheses reflect the observed number of such bids. The unit of observation for this table is the individual bid. When all (only winning) bids are considered there are 2700 (450) observations for auctions with six bidders, 1800 (450) observations for auctions with four bidders, and 900 (450) observations for auctions with two bidders. The data presented is from the sessions run at Centro Vernon Smith de Economía Experimental. 
Table 8: Estimates of models of level-k reasoning in SPUB auctions

\begin{tabular}{|c|c|c|c|c|}
\hline & \multicolumn{2}{|c|}{ Without Level 0} & \multicolumn{2}{|c|}{ With Level 0} \\
\hline & $\hat{\pi_{n k}}$ & $\hat{\lambda_{n k}}$ & $\hat{\pi_{n k}}$ & $\hat{\lambda_{n k}}$ \\
\hline \multicolumn{5}{|l|}{$n=2$} \\
\hline Level 0 & - & - & $\begin{array}{c}0.09 \\
\text { (n.a.) }\end{array}$ & - \\
\hline Level 1 & $\begin{array}{c}0.93 \\
(2099.22)\end{array}$ & $\begin{array}{c}0.12^{* * *} \\
(0.00)\end{array}$ & $\begin{array}{c}0.91 \\
\text { (n.a.) }\end{array}$ & $\begin{array}{c}0.12 \\
\text { (n.a.) }\end{array}$ \\
\hline Level 2 & $\begin{array}{c}0.07 \\
(159.58)\end{array}$ & $\begin{array}{c}0.31^{*} \\
(0.12)\end{array}$ & $\begin{array}{c}0.00 \\
\text { (n.a.) }\end{array}$ & $\begin{array}{l}14.41 \\
\text { (n.a.) }\end{array}$ \\
\hline \multicolumn{5}{|l|}{$\mathrm{n}=4$} \\
\hline Level 0 & - & - & $\begin{array}{c}0.05 \\
\text { (n.a.) }\end{array}$ & - \\
\hline Level 1 & $\begin{array}{c}0.99 \\
(3710.27)\end{array}$ & $\begin{array}{c}0.28 * * * \\
(0.01)\end{array}$ & $\begin{array}{c}0.95 \\
\text { (n.a.) }\end{array}$ & $\begin{array}{c}0.32 \\
\text { (n.a.) }\end{array}$ \\
\hline Level 2 & $\begin{array}{c}0.01 \\
(40.11)\end{array}$ & $\begin{array}{c}1.35 \\
(1.15)\end{array}$ & $\begin{array}{c}0.00 \\
\text { (n.a.) }\end{array}$ & $\begin{array}{l}3.41 \\
\text { (n.a.) }\end{array}$ \\
\hline \multicolumn{5}{|l|}{$\mathrm{n}=6$} \\
\hline Level 0 & - & - & $\begin{array}{c}0.32 \\
\text { (n.a.) }\end{array}$ & - \\
\hline Level 1 & $\begin{array}{c}0.98 \\
(3042.58)\end{array}$ & $\begin{array}{c}0.07 * * * \\
(0.00)\end{array}$ & $\begin{array}{c}0.68 \\
\text { (n.a.) }\end{array}$ & $\begin{array}{c}0.52 \\
\text { (n.a.) }\end{array}$ \\
\hline Level 2 & $\begin{array}{c}0.02 \\
(56.56)\end{array}$ & $\begin{array}{c}0.32 \\
(0.24)\end{array}$ & $\begin{array}{c}0.00 \\
\text { (n.a.) }\end{array}$ & $\begin{array}{c}0.50 \\
\text { (n.a.) }\end{array}$ \\
\hline Observations & 690 & & & \\
\hline Log-likelihood & -2206 & .11 & -39 & .03 \\
\hline
\end{tabular}

Note: Table contains parameter estimates with standard errors in parentheses, when available.

When estimating the model with level 0 bidders, the Hessian was non-invertible and the standard errors are not available, which we denote by n.a.

The unit of observation for this table is the individual bid.

${ }^{*} p<0.05,{ }^{* *} p<0.01,{ }^{* * *} p<0.001$ 


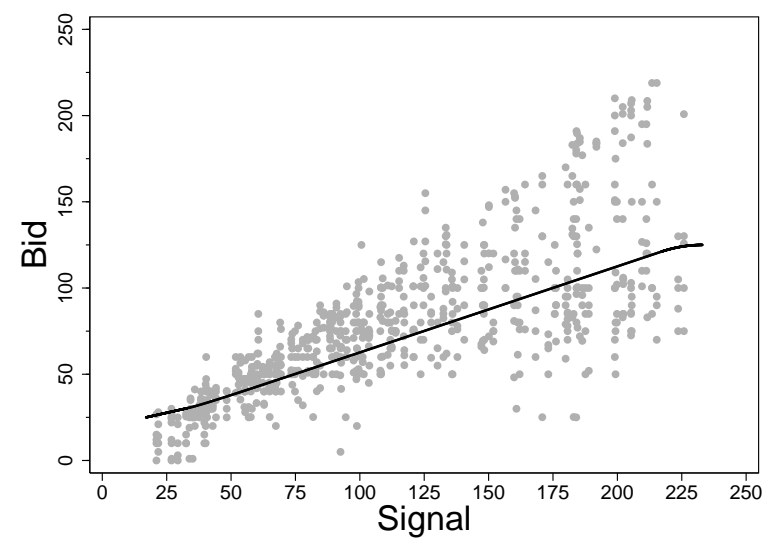

Figure 1: Equilibrium bid functions and observed bids for informed ASYM bidders. 


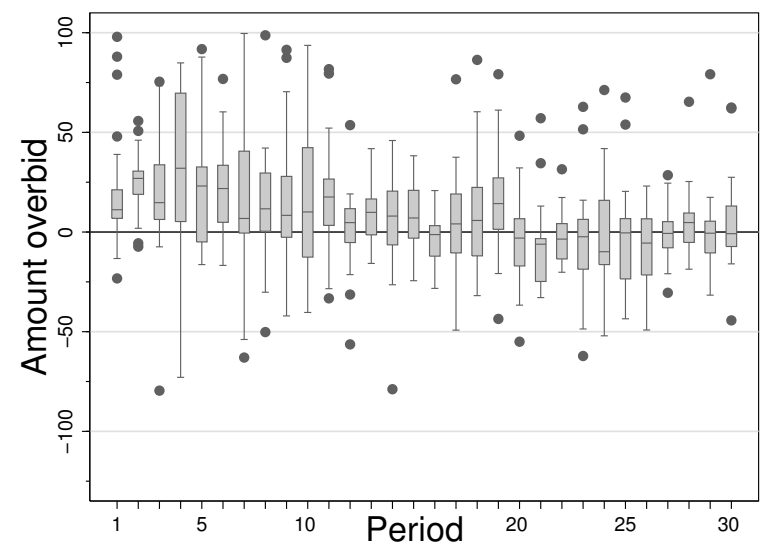

Figure 2: Boxplots of bidding relative to Nash predictions by period for informed ASYM bidders. 


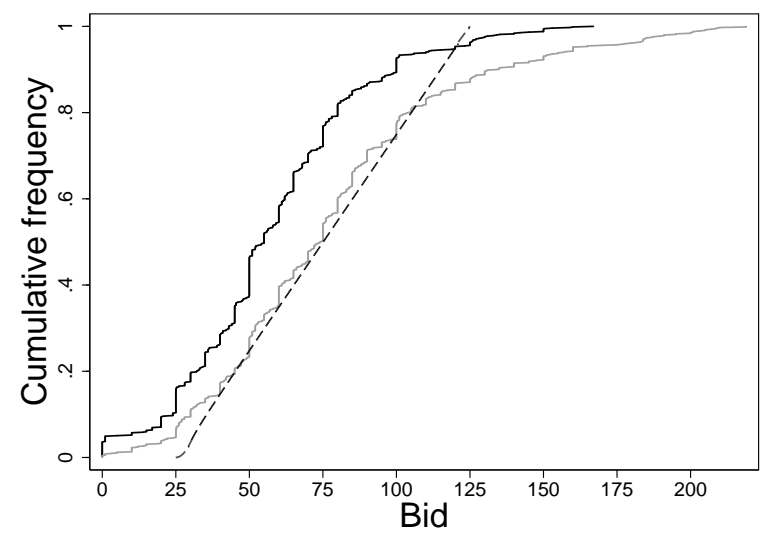

(a) All 30 periods
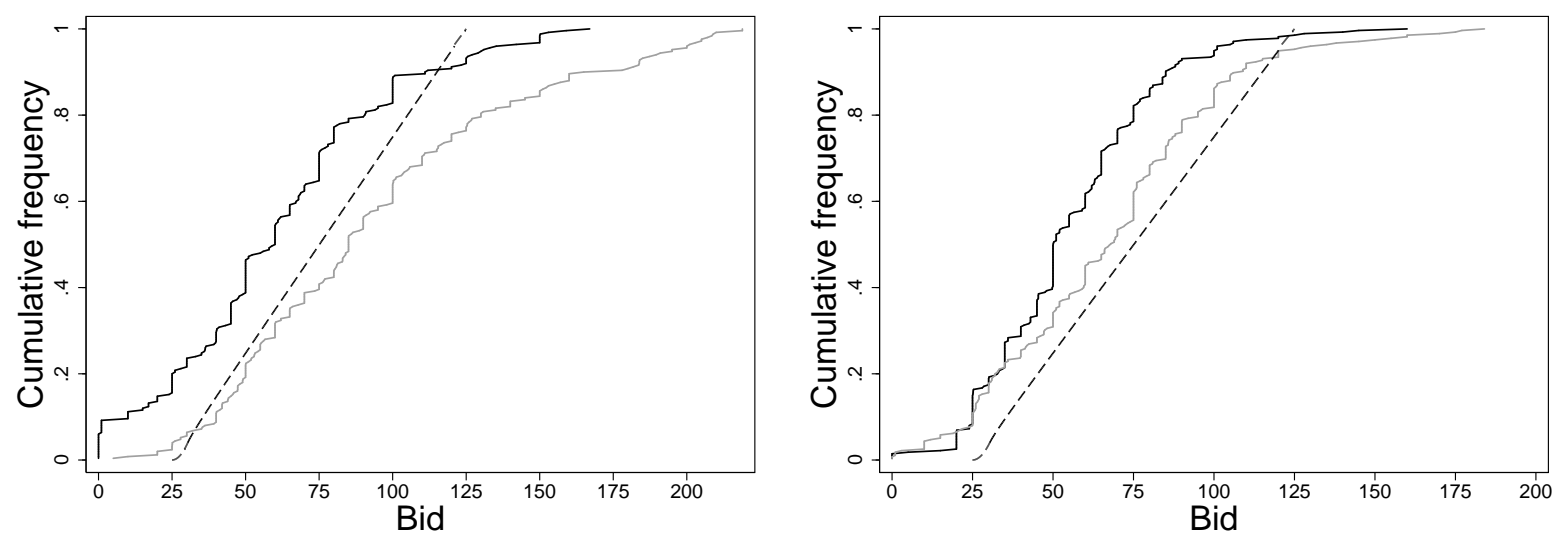

(b) First 10 periods and last 10 periods respectively

Figure 3: Cumulative distributions of bids for informed (grey) and uninformed (solid black) ASYM bidders, as well as the equilibrium distribution (dashed). 

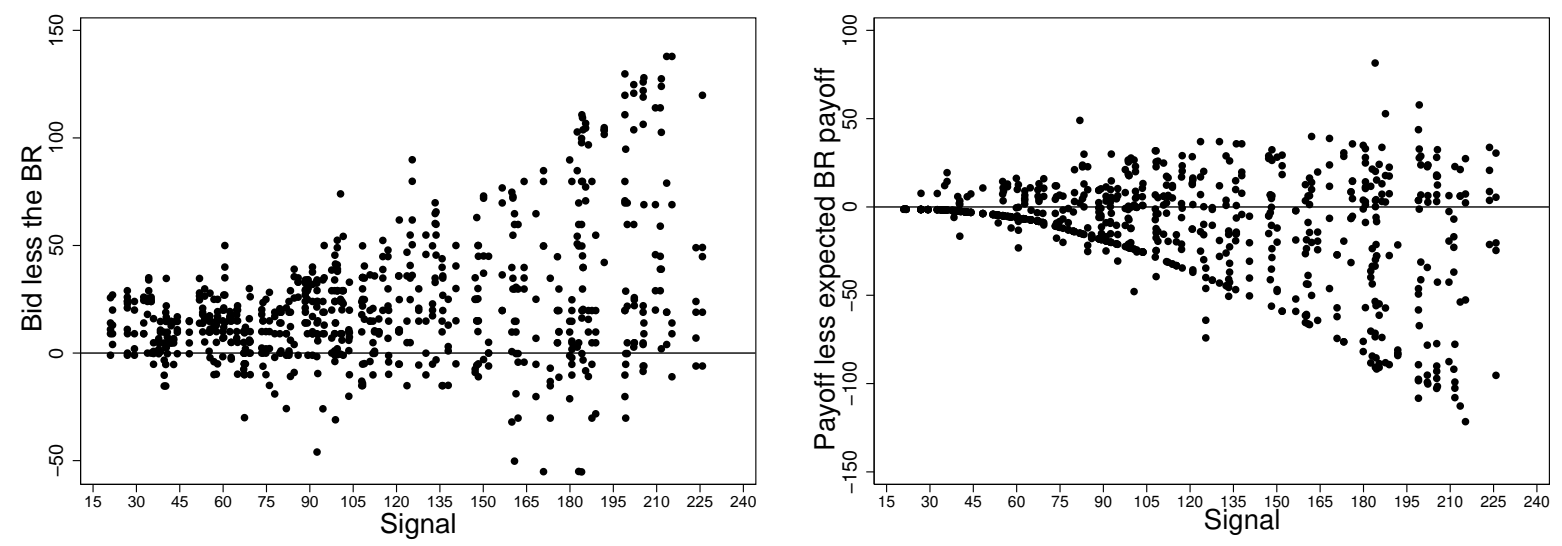

Figure 4: Observed bids (left panel) and payoffs (right panel) of informed ASYM bidders relative to the bids and payoffs of these bidders if they were best responding to the empirical distribution of the uninformed ASYM bidders. 


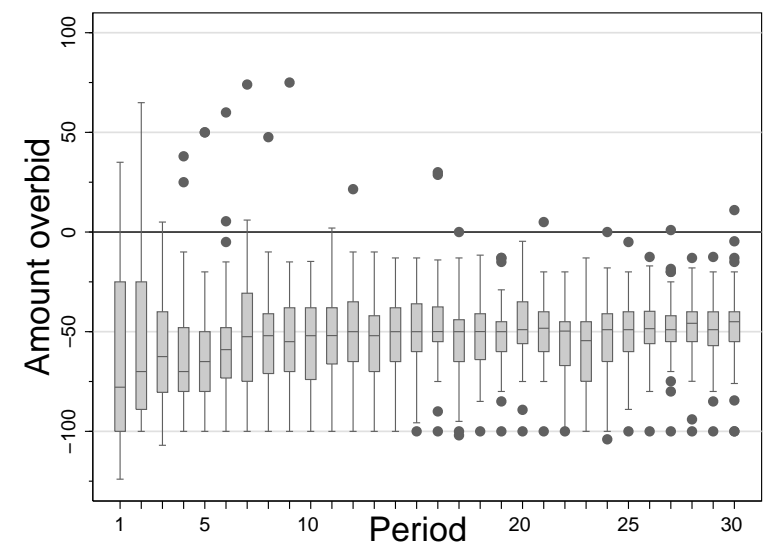

Figure 5: Boxplots of bidding relative to Nash predictions by period for SPUB bidders. 

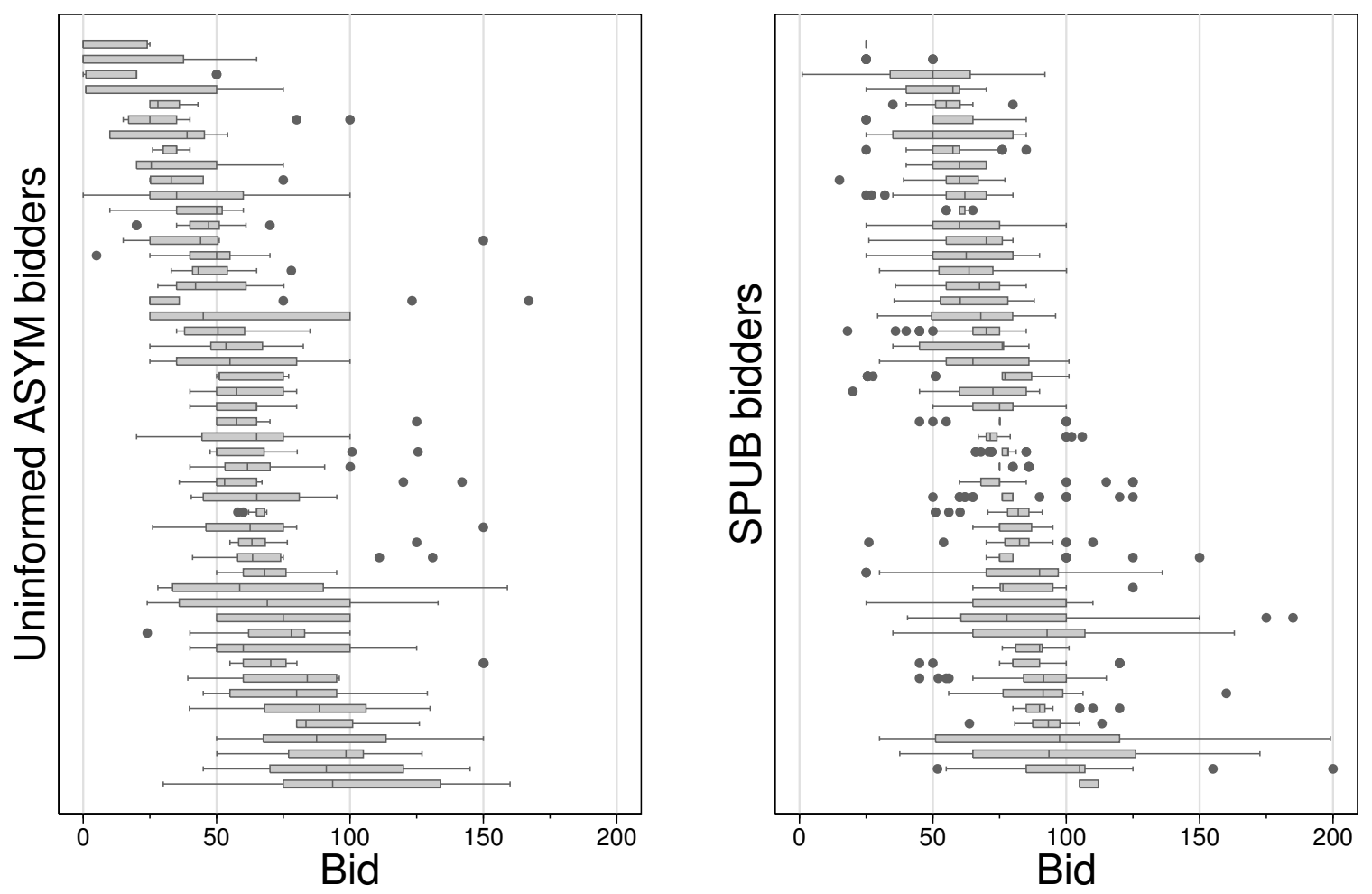

Figure 6: Boxplots of uninformed bids in ASYM (left panel) and SPUB (right panel) auctions. Each box summarizes the bids of an individual bidder, and the bidders are sorted by average bid, from smallest to largest. 


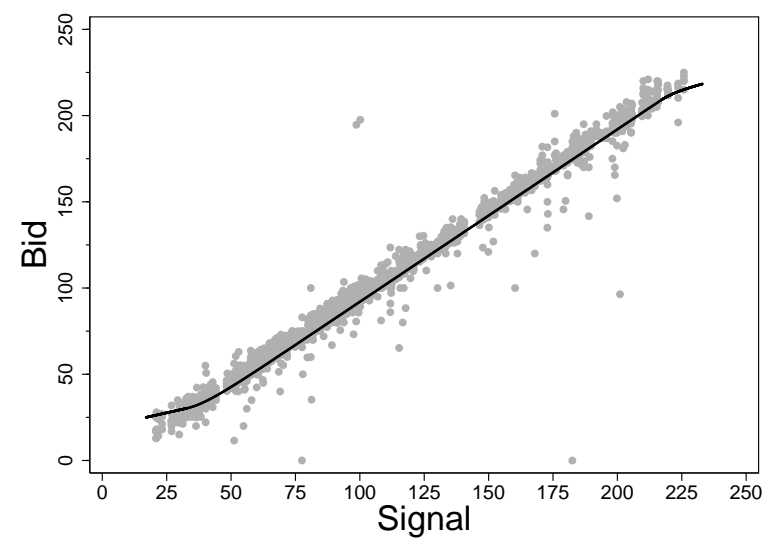

Figure 7: Equilibrium bid functions and observed bids for SPRIV bidders. 


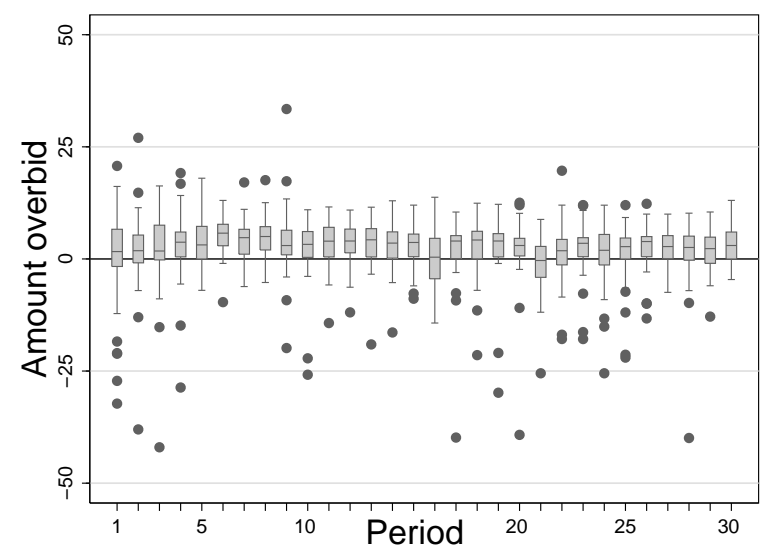

Figure 8: Boxplots of bidding relative to Nash predictions by period for SPRIV bidders. Four outliers are excluded. 

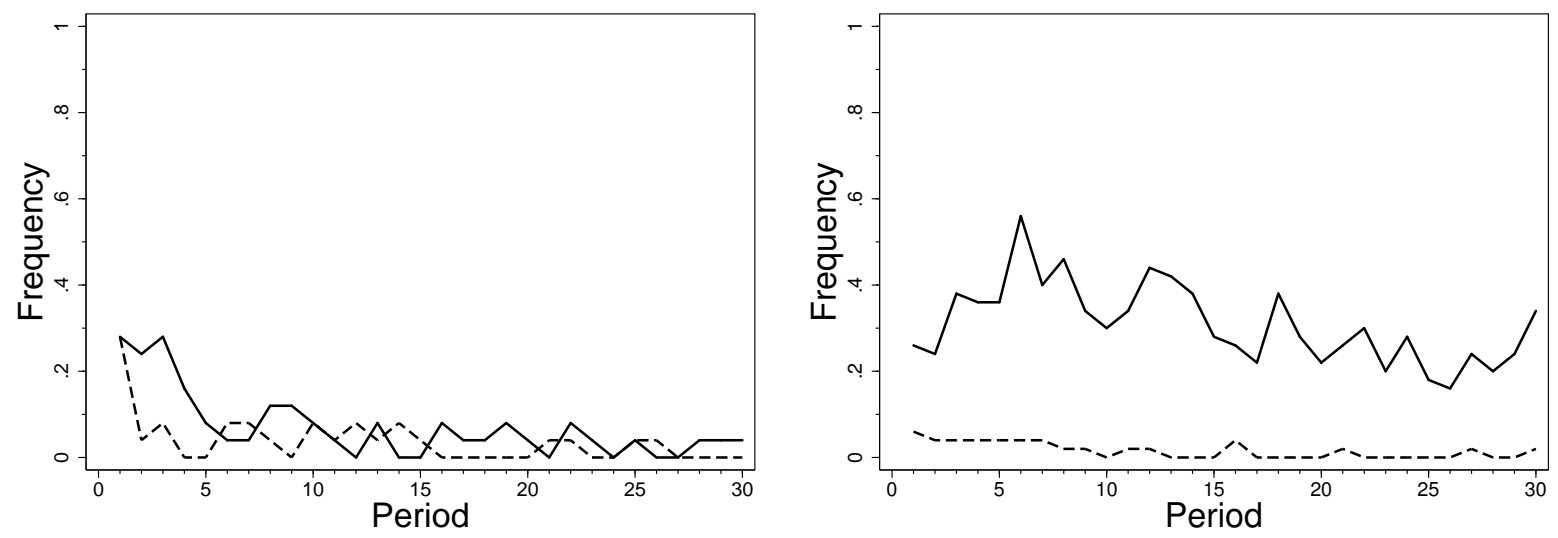

Figure 9: Frequency of bids above the break-even threshold by period for informed bidders (solid) and uninformed bidders (dashed). The left panel contains data when the information structure is asymmetric, and the right panel contains data when the information structure is symmetric. 


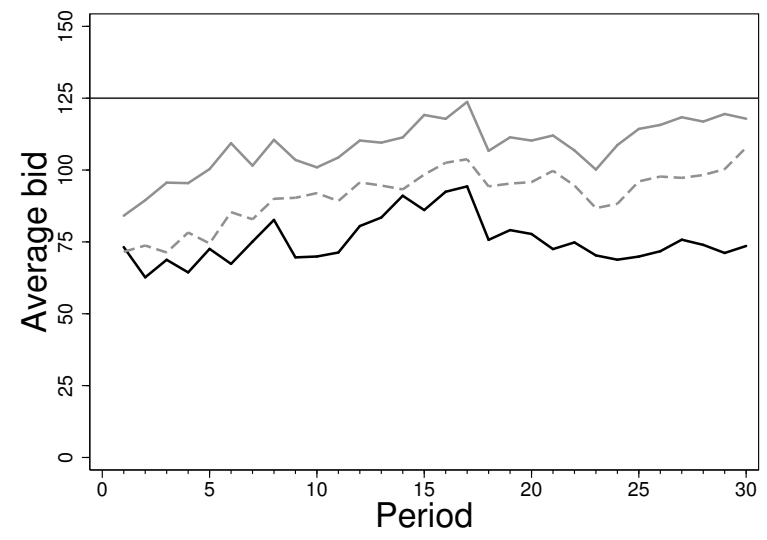

Figure 10: Average bids across periods in SPUB auctions with two bidders (solid black), four bidders (dashed gray) and six bidders (solid gray). The data presented is from the sessions run at Centro Vernon Smith de Economía Experimental. 


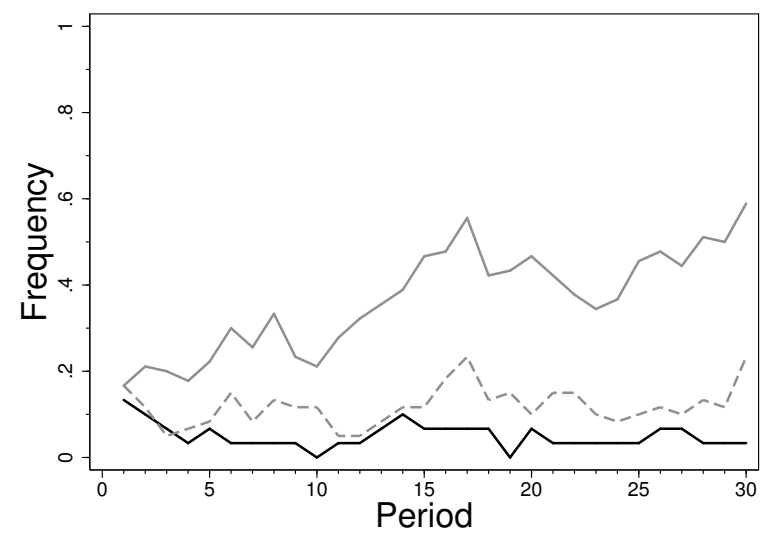

Figure 11: Frequency of bids above the break-even threshold by period in SPUB auctions with two bidders (solid black), four bidders (dashed gray) and six bidders (solid gray). The data presented is from the sessions run at Centro Vernon Smith de Economía Experimental. 


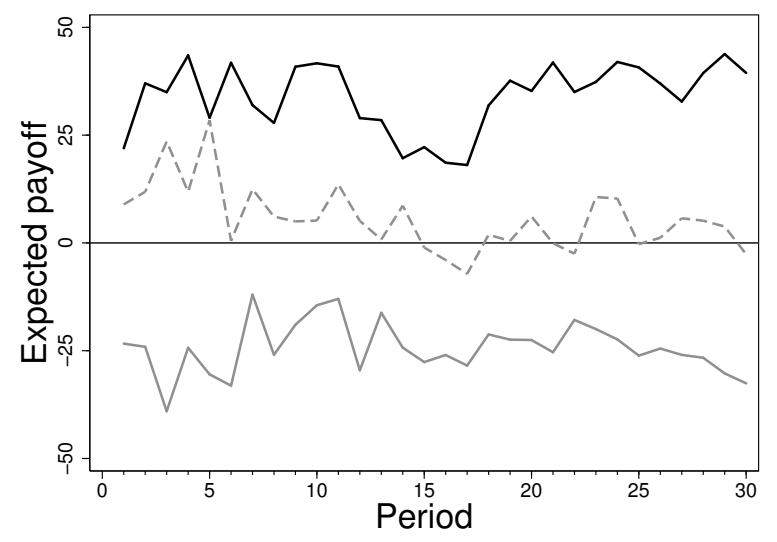

Figure 12: Average payoffs of winning bidders across periods in SPUB auctions with two bidders (solid black), four bidders (dashed gray) and six bidders (solid gray). The data presented is from the sessions run at Centro Vernon Smith de Economía Experimental. 